\title{
UNIVERSTY OF CALITORNIA
}

Lawrence Radiation Laboratory

Berkeley, Califorala

Contract No. W-7405-eng-18

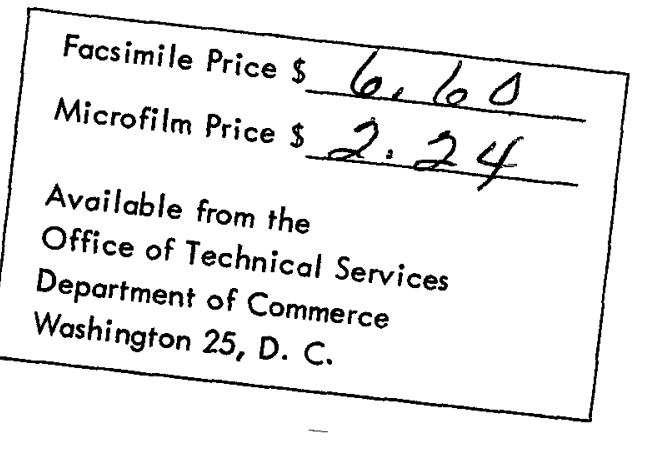

ANTIPROTON-NUCLFON CROSS SECTIONS FROM 0.5 to $1.0 \mathrm{BeV}$

Tommy tliof,, Louis Agnew, Owen Chamberlain, Herbert M. Steiner Clyde Wiegand, and Tom Ypallantio

\section{December 12, 1961}
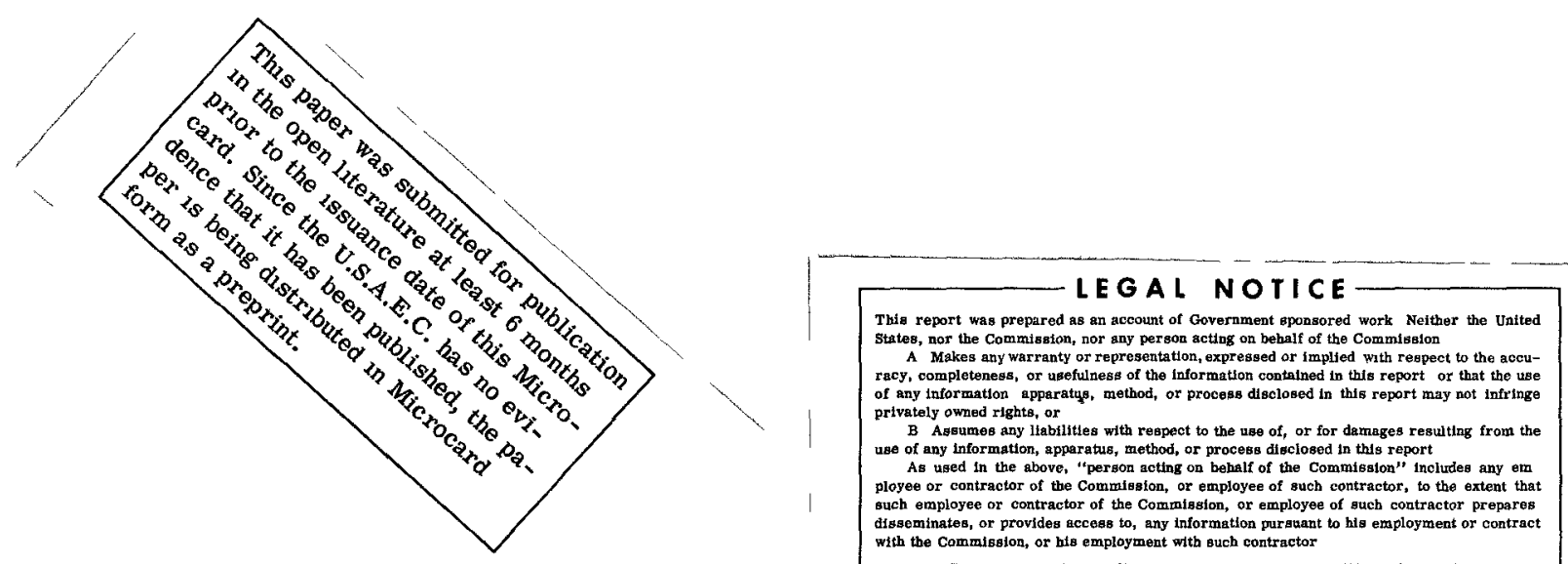


\section{DISCLAIMER}

This report was prepared as an account of work sponsored by an agency of the United States Government. Neither the United States Government nor any agency Thereof, nor any of their employees, makes any warranty, express or implied, or assumes any legal liability or responsibility for the accuracy, completeness, or usefulness of any information, apparatus, product, or process disclosed, or represents that its use would not infringe privately owned rights. Reference herein to any specific commercial product, process, or service by trade name, trademark, manufacturer, or otherwise does not necessarily constitute or imply its endorsement, recommendation, or favoring by the United States Government or any agency thereof. The views and opinions of authors expressed herein do not necessarily state or reflect those of the United States Government or any agency thereof. 


\section{DISCLAIMER}

Portions of this document may be illegible in electronic image products. Images are produced from the best available original document. 
THIS PAGE IS BLANK 
t. $y$

Antiproton-Nucleon Crose sectiona from 0.5 to 1.0 Bev

Contente

Abstract

1. Introduction

II. Apparatus

A. Antiproton Beams

B. Seam Counter

C. Antiproton Interaction Detection System

III. Procedure

IV. Antiproton Production

A. Production in Fydrogen

B. Production in Carbon

V. Antiproton-Proton Cros: Sections

A. Calculatione and Result:

3. Cox rectione and Uncertainties

1. Elastic-ocattering crona section

2. Inelastic crose section

3. Charge-exchange crovio section

C. Discuestion

VI. Determination of Antiproton-Neutron Crops Sectione
A. Antiproton-Deuteron Cross Section
B. Antiproton-Neutron Cros: Section
c. Conclusions

Acknowledgments

References 
Antiproton-Nucleon Crose Sections from 0.5 to $1.0 \mathrm{Ber}$ Tommy Elloff, Loui Amew, Owen Chamberlain, Herbert M. Steiner Clyde Wregand, and Tom Ypollantio

\title{
Lawrence Radiation Laboratory \\ Univeruity of Californda \\ Berkaley, Calternia
}

December 12, 1961

\begin{abstract}
Antiproton-production and nucleon-interaction crose sections were investigated for antiprotons in the energy range 0.5 to $1.0 \mathrm{Wov}$. The antiprotons were distinguished from other particles produced at the Bavatron by a oystem of scintillation- and velocity-eelecting Cerenkor countere. The excitation function and momentum detribution were recorded for antiproton production in carbon and compared with statiotical model expectations.

The antiproton: were directed by a syotem of bending and focuning magnets to a liquid hydgogen target. An array of plestic ecintlliation counters, which almoet completely ourrounded the hydrogen target, was ued to determine the $\bar{p}-p$ total, elastic, inelantic, and charge-exchange cross sections. Near 500 Mer the total $\bar{p}-p$ cross ection in about $120 \mathrm{mb}$, and it slowly decreuces to $100 \mathrm{mb}$ near 1 Bev. The inolantic crose section, which is princlpally due to the annihilation process, reprecente nearly $2 / 3$ of the total crove ection. The elactic scattering dietribution ie highly paked in the forward directlon and can bo fitted by an optical model.
\end{abstract}

The total and partial crose sections were also determined for the collielons of antiprotone with deuterons. Ihe $\bar{p}-d$ total and inelantic crose sectione were found to be approximately 1.8 times the $\bar{p}-p$ crose ections. Corrections were 
made for the shielding of nucleons within the deuteron in order to ascertain the $\bar{p}-n$ interaction. The resulte indlcate thet the $\bar{p}-\mathbf{p}$ and $\bar{p}-\mathbf{n}$ crose cectlone are very nearly equal in this energy region, and that they satiafy the inequalitioe required by charge independence. 
Antiproton-Nucleon Cros Sections from 0.5 to 1.0 Bev.

Tommy Elioff, Loule Agnew, Owen Chamberlain, Herbert M. Steiner Clyde Wlegand, and Tom Ypellantie

\section{Lawrence Radiation Laboratory \\ Univereity of Callifornia \\ Berkeley, Callorata}

December 12, 1961

\section{INTRODUCTION}

This report presente oux final resulte in the investigation of antiprotonnucleon crose sections in the energy range 534 through $1068 \mathrm{Mev}$. By crose sections, we mean the total $\left(\sigma_{t}\right)$, lastlc $\left(\sigma_{e}\right)$, inelastic $\left(\sigma_{i}\right)$, and charge-exchange $\left(0_{c}\right)$ cross sections. Inelastic crose section here is eynonymons with analhilation cross section for antiproton linetic energies below the threshold (208 Mev) for pion production. Above $288 \mathrm{Mev}$, the inelnatic croes eection includen both annihilation and pion production (without annihllation). A preliminary report of the $\bar{p}-p$ results has been given. 1 A portion of our reoults, together with a survey of other recent antinucleon experiments, is conteined in reporte by O. Chanberlain ${ }^{2}$ and W. A. Wenzel. 3

The particular energy range for antiprotone hore was melected to extend the lower enexgy measuremente of others $4,5,6,7$ as well as to explain an apparent contradiction in previoue results near 300 Mov. From the reaulte of earller experimente, 8,9 one would conclude that thexe was little difraction ecattering. wherean the inclastic crose section was very nearly the total crose eection. In Gharp contrast, the subsequently determined low-energy results (0 to $200 \mathrm{Mer}$ ) dieplayed a forward diffraction peak, and one found $\sigma_{0} \sigma_{1}$. The low-energy reoults were in good agreement with calculations is Ball and Chow based on 
conventional Yukawa plon-exchange mechanlem. 10 While these calculetione are not applicable above $250 \mathrm{Mev}$, a plaueible model of the $\overline{\mathrm{p}}-\mathrm{p}$ interaction advanced by Koba and Takeda 11 indicatod a eimilar bohavior at the energies under inveotigation here.

In addition to the bebic crose-section measurements we have determined the engular dietribution of $\bar{p}-p$ elastle seattering at forward angles. These resulte are compered with an optical model. For the $\bar{p}-p$ inelastic procees the amount of plon production included with the annibilation in the total inelastle crose section has been eotimated.

A further purpose of thil experiment was to measure $\bar{p}$-d lantiprotondeuteron) crose eections and thus obtain the $\bar{p}-n$ crose sections by a subtraction procedure between $\bar{p}-d$ and $\bar{p}-p$ date. Comparteon of the $\bar{p}-p$ and $\bar{p}-n$ reculte reveale the amount of interaction in the two postible leotople apin atates of the nucleon-antinucleon oyetern. These resulte are given in Sec. VI.

Whlle it had been hoped that come information on antiproton production crose sectlons in hydrogen could be obtained, it was not poselble to aseure that the $\mathrm{CH}_{2}$ taxget and the cerbon target used within the Bevatron were Irxadiated identically by the Bevatron beam. Some commente are included in sec. IV on the attempt to meavure production in hydrogen. Resulte lor production in carbon, such as the excitation function and momentum dietribution of antiprotons, axe presented. 


\section{APPARATUE}

\section{A. Antiproton Beams}

The antiproton component of the boam was electronically elected from a momentum-analyzed beam of negatively charged particles-predominantly pione. The magnetic channel that formed the momontum-analyad beam was dimilar to those of previous expertimente. 12,13 Oar syetem differed in that it wan phyalcally longex, and the momentum opread of particles traveraing the channel was ellathty larger. Specifically, the five energiea utilied were 534, 700, 816, 948, and 1068 Mer.

A schematic dlagram of the experimental area is shown in Nis. 1, and ite principal componente are identified in Table 1. The Bevatron internal proton beam atrikes elther a carbon or polyothylene target $T$. The boam duration is approximately 100 meec. To obtain $\bar{p}$ beams of the five deulred energles through our fixed eystem of magnete, we utilised eeveral target poattione (T) in the Bevatron magnetic fald region. This allowed observation of entiprotons at amall laboratory angles, which was destrable for obtalning maxdmum intonolity. Three pouitione were found (at each posttion a carbon and a polyethylene terget were used alternately) for which the magnotic channel would trensmit antiprotone in the deaired momentum range with labortory angles of emiseton between 0 and 4 deg.

We will not elaborate on the magnetlc channel, as detalle of oux partlcular eyatern here have been presented in reporte by Chemberlein 14 and TIcho. 15 The general characteristice of the beam produced by thi ayotem may be described by momentum spread $\Delta p / p$ of $\neq 3 \%$. For this interval, approximately $10^{5}$ pions and 5 antiprotons were tranomitted through the channel for onch Bovatron pulse, during which nominally $7 \times 10^{10}$ protons were incident on the Bevatron target T. More precise production rates are given In Sec. IV. 
In oxder to view the beam ize and position initially, and thereater to be certain that all magnet current were correctly ot when alterauting betwenn various Bevatron targete and different antiproton momenta, we used a device called the Beam Profile Indicator to observe the beam-intenoity dietribution vioually at any polnt in the magnetic channel. Baslcally, the Indicator is a row of 21 plaptic scintillator lements. Each scintulator hes a $1-\mathrm{cm}^{2}$ area porpendicular to the beam direction and in viewed by an MCA IP2I photomultipliex tube. When particles traveres the ecintlliatore, the proportlonate accumulated charge from each photomultipllex current is sequentially dieplayed on an oecilloncope where the beam Intenaity pattern appente as a histogram (thie device is described in detail elsowhere ${ }^{16}$ ). A typical beam pattern is chown in Fig. 2. The device could be inserted at devired positione alont the beam and could also be rotated about the beam direction to obtaln the profle in any plane through the beam direction. 


\section{B. Beam Counter:}

The countex syetem ueed to select antiprotons from the momentumanalyzed beam of negatively cherged particles conelated of three acintillution countere, $s_{1}, s_{2}, s_{3}$ and two Cerenkov counters, VSC-II and $\bar{C}$. The postione of the counter along the beam are sown in Fig. 1 , and thelr dimencione are giron in Table 1. The three scintillators were viowed by ECA 7264 photomultipliex tubes. Time-of-flight measurement between these counters rejected $99 \%$ of the plons. Effective discrimination againut the remalning plons was obtained with the Cerenkov counters shown chematically in Nig. 3.

VSC-II was a narrow-band velocity celector tuned to antiproton velocity. and eimilax to the velocity-belecting Cerenkov counter described by Wlegand and Chamberiain. 17 The function of $\approx$ was to detect particles having velocition greater than that of the antiproton (i.e.. electrons, pione, muone). Thus $\mathcal{C}$ was used in anticolncidence. As described in the following paragraphs, it was ponsble to use the ame Cerenkov radiator for both VSC-II and $\mathrm{C}$.

When a charged particle of velocity $\beta$ traverees the radiator, which hae an index of refraction $n$, Cexenkov light ie emitted at an angle with reepect to the particle direction, where $\theta$ is given by the expreselon

$$
\cos \theta=\frac{1}{\mathrm{n} \beta} \text {. }
$$

As been in Fig. 3, the refracted light then leaves the radiator at angle $\theta 1$, and is then guided by the cylindrical mirror and the three plene mirrore farranged in a triangle) to the photomultiplier tubes. The plane mirrore mexely eerve to remore the tubes from the beam. Light emitted by a particle of given $B$ reaches the photomultiplier only when the radiator, cylindrical mixror, and photomultiplier. 
have the proper separation governed by the angle $\theta^{\prime}$. These componente sllde on rails so that the counter can be easily adjuated for different velocitlea. The entire instrument is contained in a light-tight box. The light from pirticles alower or fauter than the desired velocity mises the cylindrical mirror and is absorbed by the baffle of the outer black box. Accidental counte are minimised by the requirement that all three photomultipliere give an output in coincidence.

Wgure 4 sowe the efficiency for two particular velocity settings (indicated by axrowe) of VSC-II, corresponding to antiprotons having momenta of $1200 \mathrm{MeV} / \mathrm{c}$ and $1640 \mathrm{Mev} / \mathrm{c}$. The curves were obtained by sending protons of different velocities down the magnetic channel. The afficiency if defined as the ratio of the fourfold coincidence $s_{1} s_{2} s_{3}$ VSC-II to the threefold colncidence $s_{1} s_{2} s_{3}$.

The $¥ S C-I I$ radiator material wa cyclohexene, contained is a thin-walled lucite cylinder $3.25 \mathrm{in}$. diam by $4.7 \mathrm{ln}$. long. Cyclohexene $\left(\mathrm{CH}: \mathrm{CH}\left(\mathrm{CH}_{2}\right)_{3} \mathrm{CH}_{2}\right)$ was chosen because of tte low density $(0.81 \mathrm{~g} / \mathrm{cc})$, its inabillty to scintillate, and chiefly because its refractive index was euitable for the combinatlon of VSC-II and $\vec{C}$. The optical index of cyclohexene is 1.46 at wavelength $4250 \mathrm{~A}$. This is the average useful wavelength estimated from the reaponse of the RCA 7046 photomultipliex to the portion of the Cerenkov radiation spectrum transmitted through the lucite container of the radiator and the lucite Ught pipe on the photomultipller tube.

Although VSC-II and $\mathrm{C}$ are independent countere, they utilize the same Cerenkov radiator. This is possible for a radiator with index of fofraction $(\mathrm{n})>\sqrt{Z}$. Eor this case, total internal reflection occurs for the Cerenkov light from particles faster than a certain volocity $\beta^{\prime}$. Specifically for $n=1.46$, one finds $\beta^{\prime}=0.95$. The antiprotone detected by VSC-II were in the velocity range $0.7 \leqslant \rho 50.9$, while pions of the same momenta heve $\beta>0.99$. Thus total internal reflection occure 
for the Cerenkor radiation emitted by the plons, and the 11 ght is trapped within the radiator. In order to vent this plon light and at the same time accegt neglighle Iight from the antiprotone, a lucite light pipe was optically connected to the front end of the radiator and coupled to another photornultiplier tube. The cetup is displayed in Fig. 3. Most of the light from the plone, perhape after several reflection axound the radiator, eventually reaches the 6810 A photomultiplier tube. This 1 the $\bar{C}$ countex which, when ueed in antlcoincidence with $s_{1}, s_{2}$, and $s_{3}$ (delayed for plone), rejected all but $0.015 \%$ of the pione.

\section{Antiproton Interaction Detection Srotem}

Figure 5 show a portion of the target assembly in relation to the counter syotem. The counter yatem connisted of 27 scintillation coustere which almont completely surrounded the target flask. This flask could be flllod with liquid hydrogen of deuterium.

The goometry of the counter system (Migs. 5 and 6) was designed to dietinguish the various antiproton interaction proceses. The basic idea is that the surrounding ecintillators detect all out-going charged particles resulting from antiproton interactions withtn the target (similar to the method ued by Coombeo ot al. 4). Sixteen counters, designated S-1, S-2 .. 5-16, encircled the target like the otaven of a barrol, while countera $a, B, \gamma, \delta, A, B, C$, and $D$ formed concentric ringe in the torward direction when viewed from the target. $s_{4}$ and $S_{5}$ were good-geometry counters ueed for the total-croes-eection meanuraments. These were conetructed of $0.375-$ in. -thick plautic scintillator $197 \%$ polyatyrene. $3 \%$ texphenyl, and $0.03 \%$ tetraphenyl butadienel, viewed by RCA 6810 A photomultipllers. 
Finally. the syatem was designed so that a layex of lead, approximately $0.375 \mathrm{in}$. thick (1.86 radiation lengtho) in any radial diroction from the target, could be inserted between the target and the scintillation counter in order to convert $\gamma$ rays from the neutral pions resulting from antiproton annihtlations. A simpllfed bleck diagram of the badc electronles is shown in Fig. 7 . The electrontc identifleation of antiprotone was accompliehod firet by a tast coincidence of the scintilation counter $s_{1}, s_{2}$, and $s_{3}$ in antlcoincidence with the meson counter $\boldsymbol{C}$. Another coincidence clrcuit received the elgmalo from the three VSC-II photomultipllers to produce the final VSC-II al gnal. Finally a third coincidence efrcuit placed $V S C-I I$ in colncldence with $s_{1} s_{2} s_{3} c$, and thue signaled the tranemiseion of an antiproton through the magnetic channel and ite incidence on the hydrogen target. The pion-rejection rate, 1. .., the $r$ atio of pions counted accidentally to the total number of plone that pase through the eystem, wa $3 \times 10^{-8}$. Since the ratio of plons to antiprotons was $-5 \times 10^{4}$. the re was only one accidental pion in evexy $10^{3}$ electronically ldentified antiprotons. However, even further diecrimination wae obtalned by the photographic method described below.

A. chematized in Fig. 7, the ignal from an identified antiproton, 1. e. the output of the $2 \times 10^{-8}$ coincidence, was put in coincidence with each of the counter surrounding the hydrogen target by means of the 27 two-channel coIncidence circuite. Fach of the 27 possible outputs was delayed equentially with alternate polarities for oscilloscope presentation, and each output we gated to eliminate mutual interference. The identifed $\bar{p}$ signal was also used to $t r i g g e r$ a four-beam oscilloscope, which displayed the 27 two-channel colncidence outputs along with the beam counters uwed to produce the trigger. The drawing in $\mathrm{Fig}$. 8(a) 
bhowe the positions of all poselble pulees. Traces 1 and 2 dieplay the beam countere with the exception of VSC-II. Here the Anal diecrimination agalnat the remaining pion contaminntion was made by rojection of any erent that had a $\bar{C}$ pulee, approximately one event in a thoseand. Since $s_{2}$ and $C$ had the same polarity, they were lectronicully gated so that an eccldental $\$_{2}$ pulee could not simulate $Z$, and vice verea. In addition, the time-of-alght criterion was anade more etringent by the meseurement of the relative potitione of $s_{1}, s_{2}$, and $s_{3}$ to within 2 neec. The pulee labeled $M$ in Big. $8(a)$ exe timing markere uoed to ldentify the position of the other pulese; $T_{1} T_{2}$ and $T_{3}$ are beam-epill-time indlcatora wed to Identify the Bevatron energy at which the antiproton was formed.

The oscilloscope traces were photographed on $35-\mathrm{mm}$ Alm. Ar many ae oix events could be recorded during a Bevatron pules without interference between the varioue traces. Nigure $9(b)$ is an actual photograph of the Alm in which five ovente are ween. The top trece of each of the four grouplnge is the firat event. 


\section{PROCEDURE}

$\therefore$ : When liquid hydrogen: was used as the target material; it was anrounded by the lead converter (cee Fig. 5) approximately half the time. The lead wae important to incure accuracy in the inelastic crose sectlon, as well a to indicate what fraction of the inelastic cros section was due to anmihllation. In either case. 1. e. with or without leed, rune were made in equence for the five ollected antiproton momenta and, for exch momehtum, rune were made with the hydrogen target alternately full and empty. Thla eame procedure was ropeated with deuterium as the target material.

To obtain the dealred statistical accuracy, It was necessary to have $\sim 20,000$ antiprotons incldent on the target for each crose-bection measurement. Information on $\bar{p}$ production, and on the $\bar{p}-p$ (or $\bar{p}$-d) total crose ections, was -lectronlcally monitored duxing the experiment. In order to obtain the $\bar{p}$ partial-interaction crose sections, the oscllloscope fim had to be analyzed. Analyois of the film data was guided by the fact that antiprotone ontering the hydrogen target can interact in three ways; by elantic seattering, annibilation or inelastic scattering, and charge-exchnnge. From low-energy data 4, 5,6 we know that elastic scattering is penked in the forward direction and that, upon annihtlation, 4.8 mewone (about $2 / 3$ of thom charged) are produced on the average. Therelore, half the interaction detection countere (Fige. S and 6) aurrounded the target in order to detect the major fraction of the annihilation plons. The ramaining countere in the forward direction dotected elantically ecattered antiprotons as well as ame of the annihilation plons. The central diec countero $S_{4}$ and $S_{5}$ monitored the noninterncting antiprotons. Information photographed on the oscllloscope (Fig. 8) was therafore claseged ae follows: 
(a) Pase-throumb. If the good-geometry countere, $s_{4}$ and/or $s_{5}$ were the only countere that aignaled, the antiproton paseed through the hydrogen without Interaction.

(b) Elastic ecattering. If a singlo countex of the small-angle rings counted, it was considered an elestic scattering ovent, ince the recoll proton did not have sufficient energy to leave the target. However, in the larger ringe It was poseible to have an additional counter ignal due to the recoll proton. This event was accepted as an elautic acattering only if the event wat coplanar within the resolution of the syutem.

(c) Inelatic acattering or annihilation. Thie claseified ovente in which any three or more counters algnaled. It also included those two-counter events whose geometry wad inconel stent with olastic scattering.

(d) Charge exchange. This final clasolfication wes for the events in which none of the surrounding counters gave a digal, and therefore an event of the type $\bar{p}+p \rightarrow \bar{n}+n$ was aseumed to have taken place.

A teet was made to prove our gyetem indeed capable of distingulehing between the claselfication lieted above. This test consisted of mensuring lenown proton-proton crose sections. Positive proton beams were formed by veattering 2 1.2-Bev Internal Bevatron beam from an additional target located in the region $T$ (cee Fig. 1). With all magnet curzente reversed, the $p^{+}$travereed the magnetle channel and entered the hydrogen target in precicely the ame manner as the $\bar{p}$. If the system could separate p-p elastic acattering from p-p inelantic evente normally producing only one plon these energies, it should esally distinguioh $\bar{p}-p$ elaatic cattering from $\bar{p}-p$ inelastic events in whlch up to 8 plons can bo produced upon anniblation. The p-p total, elastic, and inelastlc crose sections were meanured at 528 and $940 \mathrm{Mev}$. The results, whlch have been presented in Table III of reference 1, were found to be in excellent egreement with prevlouely meesured p-p crose sectione. 


\section{ANTIPROTON PRODUCTION}

A. Production in Hydrogen

It ocemod poseible that the crose ecetion for untiproton production in p-p collisions might be measured (by a $\mathrm{CH}_{2}-\mathrm{C}$ oubtraction) at the eame time the $\bar{p}$-interaction crose sections wero bolng meacured. The relatively high production rate in hydrogen indicated by a previous experiment ${ }^{12}$ erved as incentive to explore the production phenomenon more accurately here. Becauee an external proton beam at the Bevatron does not exiot, we approached thle phase of the experiment by utilizing the Bevatron internal beam. It was therefore neceanary to use target materiale such as $\mathrm{C}$ and $\mathrm{CH}_{2}$ and resort to a subtraction process as before. To enoure greater reliablity in the eubtraction process, target Mipping mechanieme were developed to flip efther the $\mathrm{C}$ or the $\mathrm{CH}_{2}$ targete to ldentical pouttions within the Bevatron. The $\mathrm{C}$ and $\mathrm{CH}_{2}$ targets themselves were deaigned to poseses the came aumber of carbon atome and at the eame time have identical external physical dimenuion. This wae accomplloked by cutting holee in the carbon target. A primary lip ${ }^{18}$ wan Inetalled ahead of the desired target at a distance corresponding to the half-wave length of Bevatron radial oscillatione. Heavy clipping dovicee were also stationed exound the Bevatron tank to ensure negligible probability that the internal beam protons would hit the target holders, and that they would be stopped after one travermal of the target. To minimise unknown syatematic effecte of the Bevation beam, the $\mathrm{C}$ and $\mathrm{CH}_{2}$ were uned alternately on each Bevatron pulse.

To determine the Bevatron radial position of the primary lip, obeerved production in the target was calculated approximately as a function of the lip radius. It had been expected that the characterietic shope of thil eurve would 
Indlcate Ip position at which the proton. would be focused onto the target $T$ (Fig. 1). Unfortunately, there was no agreement between the calculated curve and the observed offect, so it was not posalble to guaranteo that both $\mathrm{CH}_{2}$ and $\mathrm{C}$ target: were equally irradiated. If the targete themedves were acting to any appreciable extent an theix own Lps. then the effectiveness of the proton beam in penetrating the target: would have been abject to veriatione due to mimute misalignments.

Our reaulte showid that the $\mathrm{CH}_{2}$ target was only $95 \%$ as effective as the carbon target (with the oame number of carbon atome) bor producing $1684 \mathrm{Mev} / \mathrm{c}$ antiprotone at 0 deg. Owing to possible erroro in thit phase of the experiment. it is difficult to make a quantitafive estimate of production in hydrogen. Even with a correction for absorption in targets, our reeult: are consiatent with no production of antiprotons from hydrogen. Thus, serious doubt is cast on the earller result for $1190 \mathrm{Mev} / \mathrm{c}$ antiprotons, where production in hydrogen was found to be large with reepect to production in carbon. 12 However, the present results are still indecisive dae to uncertainties in Bevatron boam dynamice, and moxe accurate meaurements must awalt external proton beams.

Apart from experimentel difficulties, the above reeulte might be explained by the particular $\bar{p}$ momentum chosen. Laboratory momentum $1684 \mathrm{Mev} / \mathrm{c}$ was uned because antiproton of this momentum have velocity equal to the c.m. velocity reoulting from 6-Bev nueleon-nucleon collisions. From atatiatical caleulation of the antiproton c.m. momentum distribution, simllar to the method used by Amaldi et al. ${ }^{19}$ one would expect the laboratory $\bar{p}$ momentum distribution to peak at $-1684 \mathrm{Mev} / \mathrm{c}$. Hagedorn has aimilarly calculated the antiproton c.m. momentum distribution; ${ }^{20}$ however, be included the effect of final-atate interactions 
In which the $\overline{\mathrm{p}}$ can annihilate with one of the three final-otate nucleons. In the c.m. syatem, antiprotons having amall relative momentum with one of the nucleon would be expected to be most sueceptible to annihllation. This reduces the observed number of low-energy antiprotone in the c.m. gyotem, and hence those In the laboratory system, at $\sim 1684 \mathrm{Mev} / \mathrm{c}$. Unfortunately, exploration of the $\mathrm{CH}_{2}-\mathrm{C}$ difference was not undertaken at momenta other than $1684 \mathrm{Mev} / \mathrm{c}$.

\section{B. Production in Carbon}

The only previous information on the production of antiprotons at a function of Bevatron energy coneleted of three experimental polats tor $1200-\mathrm{Mev} / \mathrm{C}$ antiprotone produced in a copper target. 21 This information was not eufficient to determine the obape of the excitation function. In Nig. 9 we present the resulte of thie experiment tor the production of $1604-M e v / c$ antiprotont. The experimental polnte were determined by counting the entiprotone travereing our magnetic channol and monitoring the Bevatroh internal beam incident on our carbon target by mean. of the Bevatron induction electrodes. Corrections were made for detection effciency, tranemiseion through the magnet syotem, and absorption by matertal in the beam; therefore, the experimental pointe actually refer to production at the Bevatron terget. These correctione introduce some uncertainty in the absolute croes wection. Only the relative statletical errors are shown in $\mathrm{Mg} .9$.

Oux date can be compared with the statiotical calculatione of Amalai of al. 19 who aneuxned that in a nucleus such as carbon, the principle antiproton production processev are:

$$
p+n-\bar{p}+p+p+n
$$

and

$$
p+p-\bar{p}+p+p+p
$$


For these reactions, the crose ection was considered to be proportional only to the velume of phase epace available. The kinetic energy avallable in the centerof-mase syatem is distributed among the four find-atate particle according to statintical factors. The nucleons in the nucleus were considered to be a completely degenerate Fermi gas wh maximum energy of 25 Mev. The following formula resulted for the laboratory dietribution of antiprotons as a function of thelr momentum and angle, and also of incident proton energy:

$$
\begin{aligned}
& S_{n}(p, \mu) d p d \mu=\frac{105}{16} \frac{p^{2}}{\left(p^{2}+1\right)^{1 / 2}} d p d \mu
\end{aligned}
$$

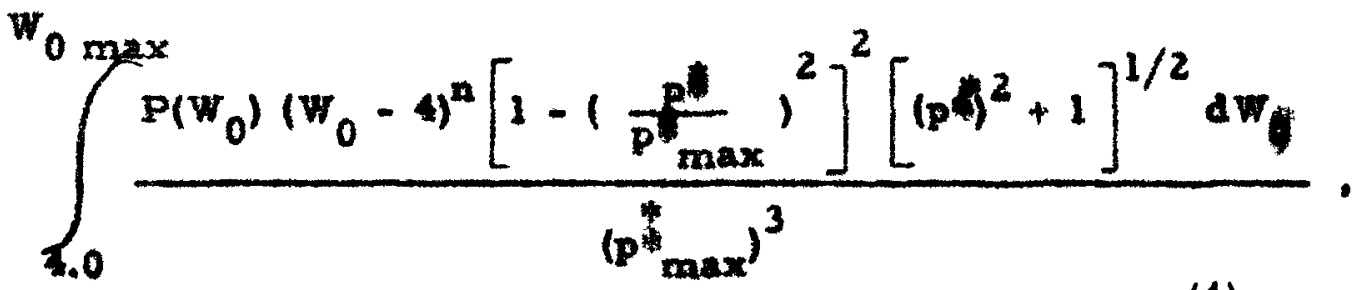

where

$$
W_{0}=\text { the total enexgy in the c.m. syotem (in proton mese unite } m_{P} \text { ). }
$$

$\left(w_{0}-4\right)=$ phase-space volume, where $n=7 / 2$ for Eq. (2), and $9 / 2$ for Eq. (3). p = antiproton c.m. momentum.

P - antiproton laboratory-systern mornentum,

$\mu=\cos \theta$, where $\theta$ is the laboratory angle of emission of the $\bar{p}$ with reapect to the forward direction,

and

$P\left(W_{0}\right) d W_{0}=$ the probability that $W_{0}$ (in the c.m. eystem) of the inctdent nucleon, and one nucleon in carbon, Hed between $W_{0}$ and $W_{0}+d w_{0}$ 
Wo have evaluated $S_{n}(P=1684 \mathrm{Mev} / \mathrm{c}, \mu=1)$ as a function of incldent proton energy for the two cases $n=5 / 2,7 / 2$. The reoults are plotted in 11 g. 9 along with the experimental data. A rather arbitrary normalization of the calculated results has been made with the experimental point at 5.1 Bev.

It is seon that the experimental values do not increase as rapidiy as expected with increasing energy, since a value of $n$ between $7 / 2$ and $9 / 2$ is prodicted for Eqs. (2) and (3) in a purely statistical model. Thus the assumption of the statistical model may not be completely valid. Other types of nuclear model: might be more appropriate for computing the function $P\left(W_{0}\right)$. It is also true that if other processes are important, aside from Eqs. (2) and (3) - such as the formation of a deuteron or helium nucleus in the final state - a amaller value for $n$ in accordance with the experimental data would be predicted. Report from CERN show that an appreciable number of deuterons, as well as some $\mathrm{He}^{3}$, are produced in 24-3er proton collioions. 22,23

In Fig. 9 one sees that the threshold for antiproton production in carbon is about 4.3 Bev. This would be expected from processes (2) and (3) when the target nucleons have a maximum rermi energy of $25 \mathrm{Mev}$, the value assumed in the statistical calculations. This feature lends support to the inftial as sumption that proton-nucleon collisions are primarily responsible here, as much lower thresholds would be noticed for reactions such as (5) and (6):

$$
\begin{aligned}
& \pi^{-}+p \rightarrow \bar{p}+p+n ; \\
& \pi^{+}+n \rightarrow \bar{p}+p+p .
\end{aligned}
$$

Such procensen can occur through a two-ntep process within the carbon target if a high-energy pion is first made by a proton-nucleon colliston. This pion then proceeds to initiate reactions (5) and (6). The threshold at the Bevation to produce a pion of aufficient onergy in carbon lagain asouming $25 \mathrm{Mov}$ for the maximum Fermal 
energy) is about 3.2 Bev. As no antiprotons were detected at our lowent energy of 4.25 Bev, our results show no evidence lor reactione (5) and (6).

Data on the production of antiprotons as a functlon of their momenta are given in Table II. where information from other experiments is also presented for comparison. 9, 4, 24 Table II (Afth col.) gives the ratio of plone tranomitted through the magnetic channel to incident protons on the target. Thle ratio is presented to ohow that the number of tranomitted plone ve momentum is relatively conetant in any given experimental arrangement, and that one is therefore able to we the pions to mbetter the relative $\bar{p}$ rates. For col. 7 of Table II we have calculated the more desirable ratio of antiprotona to incident protons. These number have been corrected for counting efficiency and loswes along the magnetic channel, wo that they actually refer to antiprotone produced at the carbon target. Although the relative values of $\overline{\mathrm{p}} / \mathrm{p}^{+}$are probably accurate, there is about a $20 \%$ uncertainty in the aboolute $\mathrm{p}^{+}$moxtiter. Becauce of this factor, and differences in the targets as well as in the solld angles of acceptance and tranemisulons of the various apectrographe, this ratio if not tabulated for the other experiments listed Lo the table.

In Fig. 10, experimental date are again compared with otatiotical reaults. 19 The curve thown is obtained from Eq. (4) for $\mathrm{n}=7 / 2, \mathrm{~T}_{\mathrm{p}}=6.1 \mathrm{\textrm {Bev }}$, and $\theta=0$ deg, and it is normalized to the experimental polnt at $1684 \mathrm{Mev} / \mathrm{c}$. It le soen that the calculation have indicated the hape of the momentum diatribution reasomably. No precise quantitative result: were obtalned for the angular diatribution of antiprotone produced at a given momentum. Qualitatively, we found in our momentum range that the production cross section at $\sim 10$ deg in the laboratory -yotem was about $12 \%$ smaller than the crose section at 0 deg. 


\section{ANTIPROTON-PROTON CROSS SECTIONS}

\section{A. Calculationf and Reoulie}

The antiproton-proton interaction events, identified by the methode dencribed earlier and claseified according to the four categorien exumerated in Sec. III. were uned to calculate the fundumental $\bar{p}-p$ erose sections by meane of the following formulas:

$$
\begin{aligned}
& \sigma_{t}=\frac{1}{N} \ln : \frac{I_{0}}{T} \times \frac{I}{I_{0}}: \\
& \sigma_{1}=\frac{1}{N} \ln \left(\frac{I_{0}}{r_{0}^{-I_{1}}} \times \frac{I_{0}^{\prime}-I_{i}^{\prime}}{I_{0}^{\prime}}\right) \\
& \left.\sigma_{0}=\frac{1}{N} \ln \frac{I+i}{I} \times \frac{I}{I^{\prime}+I_{e}}\right) \text {, } \\
& \left.\sigma_{c}=\frac{1}{N} \ln \frac{1+I_{e}+I_{c}}{1+I_{e}} \times \frac{1+I_{e}^{\prime}}{I+I_{e}^{\prime}+I_{c}}\right) \text {. }
\end{aligned}
$$

where

$I_{0}=$ the number of incident antiprotons,

$I$ = the number of pass-throughs.

$I_{i}=$ the number of inelautic evente.

$I_{e}$ the number of elastic scatters,

$I_{c}$ a the number of charge exchanges,

$\mathrm{N}$ = the number of protons $/ \mathrm{cm}^{2}$ in the targot.

The unprimed quantities in the foregoing equations refer to measurements made with the hydrogen target full; the primed quantities refor to background mesourements obtained with the target container empty. 
The andysic of all the $\bar{p}-p$ interaction evente has yielded the results given in Table III for the five $\bar{p}$ energied inveatigated here. The reublte are practically the eame as given in an earlier report in which $-60 \%$ of the data were analyzed. 1 Slight changes on the order of 1 to $2 \%$ sen in the table rovult from the inclualon of all the data; coneequently, mallex orror are reported here.

The angular dietribution of $\bar{p}-p$ elaetic scattering is shown in Fige. 11,12 , and 13. Most of the elestic catters are contalnod with a cone of half-angle 10 deg (center-of-mass). Although our syotem could also detect the elantic ecattering from 40 to 135 deg (center-of-mase), the angle could not be reaclved in this cave. The experimental points at 0 deg are lower limite determined by meane of the optlcal theorem from the total-cwese-eection measurements. In Fig. 13 we have plotted the data of Armenteros et al. for comparison, who performed their experiment with techniques aimilar to this experiment, ${ }^{24}$ but had better angular resolution, especially at large angles. The two ets of data are in very good agreement.

The curves shown in Migs. 11, 12, and 13 were calculated by means of the optical model of rernbach, Serber, and Taylox, ${ }^{25}$ In which the ecattering amplitude, diffraction croas section, and absorption crose mection are given reepectively by

$$
\begin{aligned}
& f(\theta)=\frac{1}{\pi} \int_{0}^{\infty}(1-a) J_{0}\left(\frac{2 p}{k} \text { ain } \frac{\theta}{2}\right) p d p . \\
& \sigma_{0}^{\infty}|1-a|^{2} p d p .
\end{aligned}
$$

and

$$
\sigma_{1}=2 \pi \int_{0}^{\infty}\left(1-a^{2}\right) p d p .
$$


For an incident ware of unit amplitude and sero phece, a the emplitude and phase of the transmitted wave; $p$ is of course the distance from the cattering center, meacured in a plane orthogonal to the incident-wave direction. The particular $p$ dependence of a used by Armenteros et al. ${ }^{24}$ was

$$
\begin{aligned}
& a=0, \quad \text { for } 0<p \leqslant R_{0}: \\
& a=1-\exp \left[\frac{p^{2}-R_{0}^{2}}{p_{0}^{2}}\right], \text { for } p>R_{0} .
\end{aligned}
$$

Thie coxremponds to a bleck region of total absorption having radiu $R_{0}$ eurrounded by a region where the aboorption decreases exponentially from $\mathbf{R}_{0}$ with increalng The values of the parameters $R_{0}$ and $P_{0}$, dotermined from the experimental crose cectione, appear in Table IV. The values from reforence 24 are aleo shown. To obtain theee parametere, our crose sections at 700 and 816 Mev were avernged for the calculation at $758 \mathrm{Mev}$, and those at 948 and $1068 \mathrm{Mer}$ were combined to calculate the angular distribution at 1000 Mev. This was done because the angular distributions at these energies were nearly identical.

Oring to our lack of Information at large angles, a comparison between various denelty distributions other then those in Xq. (14) is not feasible. It was ohown, however,inireference 24, that the conditione of Eg. (14) give a better fit to the data at $980 \mathrm{Mev}$ than a model of a completely grey regton does.

It is of interest to connider the behavior of the inelastic crose section above the threehold for meson production. The inelantic cress vection ae defined earlier is due to the annihilation proces below $288 \mathrm{MeV}$, whlle mbove thie energy the following reaction may be included: 


$$
\begin{aligned}
& \bar{p}+p-\bar{p}+p+\bar{p}^{0}, \\
& \bar{p}+p-q+\bar{p}+\bar{q}^{+}, \\
& \bar{p}+p-\bar{p}+p+\bar{p}^{-}, \\
& \bar{p}+p-\overline{\mathbf{n}}+q+\bar{q}^{0} .
\end{aligned}
$$

(Double-plon production is nogligible bolow 1 ber, as is the case in the p-p and n-p internctione. 26, These procesees have the detdactive feature that only two charged particles are produced in the final atate, except for procese (18) in which the gemmas from the ${ }^{0}$ decey might appear upon converaten al one ox two "s charged particles; thus the analyate of our one-and two-particle inelastic orants obtained with the lead converter allows wo to eutimate the crose sectlon for (16), (17), and (18). The same procedure cannet be used for (15) whout the lead converter, because this proces is not distingulohed by our counters from the more abrundant annihllation mode

$$
\bar{p}+p-n^{+}+\pi^{-}+z n^{0}
$$

Wo find that inelastic processen (16), (17), and (18) taken together compose $5 \pm 3$ mb of the inelastic croes section at each of the $\bar{p}$ entrgtes of this expariment. Thio result is in agreement with the more accurate date of Xuong of 2 . for $930-$ MeV antiprotone in the Bexkeley 72-inch hydrogon bubble chamber. 27 Thoy obtain 1.6, 1.1. and $0.96 \mathrm{mb}$ respectively for processen (15), (16), and (17). 


\section{B. Corrections and Uncertaintiee}

The errors quoted in Table III are the standard deviatlone due to counting atatietice togethex with the eatimated uncertainty in the following correctlons.

\section{The Total Crose Section}

The total crose sections were corrected for forward ecattering. This wae done by measuring the crowe sections at three dfferent cutoff angles (3, 4.2, and 5.3 degl determined by counter $s_{4}$ and $s_{g}$. These reoulte were plotted ve colld angle (determined by the cutoff angle) and extrepolated to cero solld angle by a otrafght-line least-squares fit. The result gave the ane correction factor at one would obtain by voing the optical theorem ${ }^{28}$ and the agoumption $d \sigma / d \Omega\left(0^{\circ}\right) \approx I_{0}^{2}$. where $I_{0}$ it the imaginary part of the forward-scattering amplitude. This correction factor ( 3 deg to 0 deg) amounted to approximately $2 \mathrm{mb}$.

Small corrections of the order of $1 \%$ to $2 \%$ have been made for accidontale and tor annihllations in counters $S_{4}$ and $s_{5}$. The acejdentale are due to the high Aux of neutrone in the Bevatron experimental area. The concrete shielding around area A (Fig. 1) was not sufficlent to eliminate this beckground entirely. To dotermine the accidental rate, a number of rune were made during which the $\bar{p}$ trigerer from the $2 \times 10^{-8}$ sec colncidence (Fg. 7) was pat out of delay whth reopect to each of the 27 signale from the counters enclrcling the bydrogen target. The oscilloscope traces were photographed an in a normal run. Any palses that occurred during this time were due to the accldental counts. The resulte ahowed that an average counter had a probability of $-1.5 \times 10^{-3}$ for counting accidentally during a real event. Corrections were made for this affect in the analy eis of the rarious events. 


\section{Elevtic-Scattering Crose Section}

The eame correction for forward sattering has been made as in the total cross section, as well as similar corrections for accidentals and anaihilations in countere. An additional correction $(\sim 1 \%)$ has been made for scatteringe that find thair wey through emall cracke botween counters and so simulate charge exchange. No correction has been made for buckward-scattered antiprotons that may not have eufficient energy to leave the target and hence annihllate in the hydrogen, because of the uncertainty in the angular distribution at large angleo. However, othex experimenta. In which the angulax distributione are known to laxge angles, $5.7,29$ indicate that this correction is emall $(\leq 1.0 \%)$.

\section{Inelactic Crose Section}

Here, corrections for annihilations in counters and for accidentals have also been made. We note that annihllation evente of the type $\bar{p}+p \rightarrow \pi^{+}+n^{-}+n \pi^{0}$ (where $n$ is an integer of average value $\sim$ ) can be distingulohed from elactic scattering chiefly becauge of the coplanarity condition. This was vertitied when the lead converter was used and the number of elastic scattering events remained unchanged. The particular annihilation mode, $\bar{p}+p \rightarrow \pi^{+}+\pi^{-}$, cannot of cource be dietinguished from elastlc cattering by our system. However, this mode bas been estimated from bubble chamber experimente to constitute 168 than $0.3 \%$ of all annihilutions. 5,26 The other possible annibllation modes are unambiguous.

\section{Charge-Exchange Croes Sectlon}

For the charge-exchange crose sections, correction have likewine been made for antineutron annihliations in the ourrounding countere, for accidental events that would make a charge exchange appear as a paes-through of lactic ecattering. and for the umall fraction of small-angle elastic ocatteringe that would normally 
be counted in only one counter, but can occastonally traval through a crack between countexs and be recorded as a charge-exchange orent. A correction has aleo been made for anathllations that produce $\nabla^{0}$ mesone only. Provious experimente indicate that poselbly $20 \%$ of the charge-exchange crose section (as determined here when the lead converter wae not ueed) could be due to "mexo-prong annihdiations". 5,6 Thie amount to about $1.5 \mathrm{mb}$. Low-energy theoretical calculatione agree with this eatimate. ${ }^{30}$ and our resulte determined with lead converter corroborated an effect of about this nise.

The data taken without lead convertex included the procese $\bar{p}+p-\bar{n}+\mathrm{n}+\mathrm{x}^{0}$ as part of $\sigma_{c}$, while for the data with lead converter this procese if recorded as part of $\sigma_{1}$. Since the crowe ection for this procese is yot unknown, we have made no corxection, howevex it to belleved to be $-1 \mathrm{mb} .26,31$

\section{Discuesion}

The results for the $\bar{p}-p$ cros section given in iable III are plotted in Ngo 14, to compare them with the cross sections obtained by others at nearby $\bar{p}$ energies. $4,5,8,9,6,24,32$ Ond sees a reaconable trandition between the low-energy croes nections and thos determined by this experiment. There is excellent agreement between our higheat-enexcy points and the data of reference 24 . In the energy interval of this experiment the general tread of the $\bar{p}-p$ cxose cectiona is a low decrease with Increasing enexgy; the cross sections vary approximately as $T_{\bar{p}}^{-1 / 2}$, where $T_{\bar{p}}$ to the $\bar{p}$ Inboratory-oyatem kinetic energy. Although the charge-exchange crose wection appeare nearly constant, it is not inconeistent with the energy dependence of the other crose sections. Our valued for the charge-exchange crose esction axe in agreoment with other duta (obtained by different mothode) not presented in Fig. 14. For example, Weingert of al. obtalned the value $10.9+5.8 \mathrm{mb}$ 
at 455 Mev. ${ }^{33}$ They uod a $\mathrm{C}$ and a $\mathrm{CH}_{2}$ target to initiate the charge exchange and a laxge block of plastic ecintlliator to detect the antineutron annibilatloa. The experiment of Fingrich et al. utllieing 930-Mev antiprotone in the 72-inch hydrogen bubble chambex hat ylelded value of $7.840 .6 \mathrm{mb}$ tor the charge-exchange croes action. 31

We have discused in a provious report the puseling situation createril by earller experimental reeulte neax 500 Mev.' An seon in Fr. 14, these data Indicated a large absorption crose vection with 1 ttlle difraction ecattering. 8,9 The eituation ceme largely recolved, as our present data bhow the difraction sectering near 500 Mev to be $-1 / 3$ of the total crose section.

In the antiproton energy range 50 to $250 \mathrm{Mer}$, the $\bar{p}-p$ crose sectlone are underatood in terme of the theory of Ball and Chew. 10 Their modal atrenses the andogy botween the $\bar{p}-p$ and the nucleon-nueleon systems. They tee the Cartenhaus-5ignoll-Marshak potential. 34,35 which seome to represent the nucleonnucleon interaction up to about $200 \mathrm{Mev}$, and modify it suitably for the antinucloon case. The rosult is that a nucleon appears to an antiproton as black hole or core region, surrounded by a potential due to the pion cloud. The earller experimental data (also ohown in Fig. 14) lend support to this model. In the energy range of applicability, 1. $\theta ., 50$ to $250 \mathrm{Mev}$ one finds $\sigma_{e} \approx \sigma_{i} \approx \sigma_{t} / 2$. Thus the $3 a l l-C h e w$ model in ita predictione is very nearly like a claselcal black-sphere region of ofre * (pion Compton wave length). This is explatned by the effectivenes of the outer potential due to the plon cloud which drawe the $\bar{p}$ into the core region where it annililates.

The methode ueed in the Ball-Chew calculations render them inapplicable in oux energy range. However, a model along the eame trend of ldeas bae been proposed by kohn and Takedn. 11 Their predictions are applicable at our energles 
and accord with our measured cross sections. Their model consiats of a completely phenomenological core region ourrounded by a plon cloud. The core region is likened to a black sphere whose rtdius a is left as an adjustable parameter. Outside the core region is the potential owing to the pion could, which they surmise can be calculated in principle by meson theory at high energies in a manner perhaps similar to that of Ball and Chew for low eaergies. It is expected that the pion potential will become less effective as one approucbes bigh energies, and the annibilation cross section should become $n a_{0}^{2}$. This feature has also been polnted out by Chew. ${ }^{36}$ Koba and Takeda considered the effect of the core region alone. As the clasulcal approach is not valid in the energy region 300 to $800 \mathrm{Mev}$, they solve the Schroblinger equation and obtain

$$
\sigma_{a}=\left(a_{0}+k\right)^{2}
$$

for the annihilation crose section, instead of the claselcal reault $\sigma_{a}=v_{0}^{2}$. It is found that higher-order partial weves that classtcally would never reach the core can be pertially absorbod; thue the aboorption crose section is increased relative to the scattering crose section. Koba and Takeda find for $a_{0}=2 / 3 n_{\pi}=0.99 \times 10^{-13} \mathrm{~cm}$ that the ratio of the elantic scattering crome wection to the annihilation crose eection is $1 / 2$. From our experimental data in Fig. 14 one wees that $\sigma_{e} / \sigma_{i}$ is $1 / 2$ near $1 \mathrm{Bev}$, and only elightly larger at 534 Mov. The data for $\sigma_{i}$ can very nearly be fitted by Eq. $(20)$ for $a_{0}=0.95 \times 10^{-13} \mathrm{~cm}$. For this value the high-energy polnte He llightly above the curve, but this might be accounted for by a difference between $\sigma_{i}$ and $\sigma_{a}$, because of pion production.

The optical-model analyole of the angular diatributions of the $\bar{p}-p$ elaatic cattering indicate a rather large opaque nucleon itructure. In the region mear $300 \mathrm{Mev}$, the differential cattering can be fitted by a completely black region 
of radiue $-\lambda_{n}$. In the preceding section, it in ceen that our date from 534 to 816 Mev can be fitted by a black refion of rediue $2 / 3 \lambda_{\pi}$, parrounded by a region of decreaning grayness. Stmilar conditions exiet up to 2 Bev, an ohown in Table IY.

In view of the above observatione it is not unxeavonable to think of the $\bar{p}-p$ interaction region es having a etructure whose total oise in $\sim n_{n}$, withlo which the core region where annihilation taken place may be as large at $2 / 3 k$. While argumente from meson theory favor a smaller annibliation reglon of the order of $k_{p}=\left(0.21 \times 10^{-13} \mathrm{~cm}\right),{ }^{37.38}$ Tamm has pointed out that a larger core reglon $1 \mathrm{~s}$ within the realm of theoretical expectatione. 39 Perhape the determination of the p-p partial crose sections in the muld-Bev reglon will yleld further information on this point. 


\section{DETERMINATION OF ANTIPROTON-NEUTRON CROSS SECTIONS}

In order to underetand the antinucleon-nucleon ayetem completely,infermation munt be acquired not only for the $\bar{p}-p$ interaction, but also for the $\bar{p}-n$ (or $\bar{n}-p$ ). As in the nucleon-nucleon caes, one can then dotermine the amount of tnteraction In each of the two postible lsotopic upin (I) atates of the antinucleon-nucleon eystern. The $\bar{p}-n$ eystem is purely $I$ i 1 state, while the $\bar{p}-p$ syotem exdets with equal probability in both $I=1$ and $I=0$ otatee. Teate for the valldity of charge indepandence can thus be made from a knowledge of the $\bar{p}-p$ and $\bar{p}-n$ cress cections.

The experimental factors involved in the determination of the $\bar{p}-p$ crose nectione are coneiderably more attractive than those for the $\bar{p}-\mathrm{n}$ or $\overline{\mathrm{p}}-\mathrm{p}$ crose ecclone. For the former, $\bar{p}$ beams exdat, hydrogen targets are at hand, and both particlea involved are charged. In the latter, one is faced with the nocestity of providing a neutron target or an antinoutron boam, in addition to the difncult feature of detecting a neutral particle. The feablblity of obtaining antinoutron beams utilizing the reaction $p+p \rightarrow \bar{n}+H^{3}$ wae investigated by Moyer ot $a . .^{40}$ the procedure wan found very difficult. However, the wee of entineutrons from the $\bar{p}-p$ charge-exchange process ceem to offer promlee. 31

The other elternative, chosen here, is to make indirect use of a noutron target va the deuteron. The hydrogen target used to obtain the $\bar{p}-p$ crose sectione in Sec. $V$ wae equally capable of containing deuterium, and a supply of antiprotone was at hand. Thus in principle, the unbtraction of the $\bar{p}-p$ crose pections from the $\bar{p}-d$ crose sections could be made, and values for the $\bar{p}-n$ crens section aseseed. To this end we have determined the $\bar{p}-d$ crose ectiond at the same fve energies as the precoding p-p data. The $\bar{p}$-d data are presented firat, en thel valldity eeems secure because they are secertained in the same mamer as the $\bar{p}-p$ reeults. 
The enbersction procedure used for the $\bar{p}-n$ values, oubject to wome uncertainty. is discused in the enbequent rectlon.

\section{A. Antiproton-Deuteron Cross-section}

The vartous types of $\bar{p}-d$ interaction 1.4. ocattering, annihtintion, atc., were identified in the manner outlined in Sec. Ill. Calculation of the cross aections and correction factore was performed by the method already montioned for the $\bar{p}-p$ crose action. The results are listed in Table $V$ and plotted in $\mathrm{Ng}_{\mathrm{g}}$. 15 .

No distinction can be made by our detection oyotem botween elastic $\bar{p}-d$ scattuating and quad-elantic $\bar{p}-p$ or $\bar{p}-n$ ecattering. Obeervations of the correoponding $\mathrm{p}^{+} \mathrm{d}$ reaction at $660 \mathrm{Mer}^{41}$ indicate, however, that the probublity that the deuteron remain intect is quite mall. Because of the predominant forward scattering, only about $20 \%$ of the scatterings axe accompanied by a recoll proton with oufficient energy to escape the target. For the data taken without the lead converter some $\bar{p}-P_{d}$ elactle scatter may not be distinguiabed from the $\bar{p}-P_{d}$ two-charged-plon annihilation mode (see Eq. 19) becaupe of the deuteron internal momentum ( $\mathrm{p}_{\mathrm{d}}$ refere to the bound proton within the deuteron). Comparieon of runs with and without converter has whown, however, that the effect is within the limits of our statietical errors. The difference between lead in and lead out aleo revealed no amblguity between the majority of the elatic acatteringe, in which no recoil nucleon was detected, and the $p-n_{d}$ one-charged-pion ansihilation mode.

An additional amall correction to the elastic ocattering may result from the meeon-production procese (or inelaetlc charge exchange), $\bar{p}+\mathrm{a} \rightarrow \overline{\mathrm{n}}+\mathrm{n}+\overline{\mathrm{n}}^{-}$. Judging from the magnitude of the cros aection for tmilax procescen in the $\bar{p}-p$ cane, one would not expect this reaction to be more than $-1.0 \mathrm{mb}{ }^{31}$ 
From FUg. 15, it is seen that the energy dependence of the $\bar{p}-d$ crose vectlone is very aimilar to the $\bar{p}-p$ results. The total and Inelaetle crose wectlone are 1.8 times the correaponding $\bar{p}-p$ cross sections, while the factor for elastle scattering 15 approx, 2.0. The charge-exchange cross sections are slightly smaller in deuterium. We recall that the charge-exchange procese can occur only for the proton; consequently onemight expect the same ralue for $\sigma_{e}(\bar{p}-p)$ and $\sigma_{e}(\bar{p}-d)$. However, the ehadow correction discussed in the next section would reduce $\sigma_{c}(\bar{p}-d)$ relative to $\sigma_{c}(\bar{p}-p)$, as is observed. The only other existing datum tor the $\bar{p}-d$ reaction (obtained by Cbamberlain et a. ${ }^{8}$ ) has also been plotted in Fig. 15. If is in agreement with on reoults.

\section{B. Antiproton-Neutron Crose Sectione}

Experimental ifformation on nucleon-deuteron and nucleon-nucleon crose sectlone at high energies ( I Bev) indicates that the oum of free-nucleon crove ections is approximately $10 \%$ greater than the deuteron crose section. Thue a quantitative expreation for the deuteron creos aection, where $x$ is the incident particle, munt be written as

$$
\sigma(x, d)=\sigma(x, p)+\sigma(x, n)-C
$$

where $C$ is a correction factor cometimes called the "eclipee" or "shadow" factor. This correction is due to the partial shielding of one nucleon by the othex within the deuteron.

The shadow factor was studied in dotall by Clauber. 42 By means of diffraction theory Glabex has calculated a general expression for $C$ in terms of the outgoing-wave amplitudes and phases. In view of the lack of knowledge of these factore, he develope an approximate formula for the correction factor of the total cros: sections,

$$
C_{t}^{*}=\frac{4 \pi}{k^{2}} R e\left\{f_{p}(0) f_{a}(0)\right\}\left\langle z^{-2}\right\rangle_{a} \cdot
$$


where $f(0)$ refers to the forward scattering amplitude, $I$ is the neutron-proton eppration. and the angular parentheses refer to an average value in the douteron ground state. The recult of Eq. (22) is very almilar to what one would obtain by a eimple claselcel computation of the decrease of incident fux when one nucleon to In front of the other; however, the work of Clauber differs in that the coberent diffraction acattering of the two nucleone is taken into account. One of the mjeor approximations made for the perticular expression (22) is that $x$ is larger than the aucleon-interaction range. Under the additional aseumption of a purely abeorptive Interaction, Gauber obtaine, for the total deuteron cross sectione,

$$
\sigma_{t}(x, d)=\sigma_{t}(x, p)+\sigma_{t}(x, n)-\frac{1}{d t} \sigma_{t}(x, p) \sigma_{t}(x, n)\left\langle x^{-2}\right\rangle
$$

For the abeorption crose section the relation

$$
\sigma_{1}(x, a)=\sigma_{1}(x, p)+\sigma_{i}(x, n)-\frac{1}{2 \pi} \sigma_{1}(x, p) \sigma_{1}(x, n)\left\langle x^{-2}\right\rangle d
$$

is found. A almilar expreselon for the scattering crosa wection can also be determined. 42

To calculate the lant term in the last two equatione, the deuteron wave function muet bo known. Three different wave functions corresponding to a sunrewell potential, Hulthen potential, and an attractive potential with a hard core were ueed previously to eatimate $\sigma_{t}\left(x^{-}-d\right)$. The respective resulte tor the laot term in Eq. (23) were 4.2, 5.3, and $3.3 \mathrm{mb} .43$ The experimontal result in the plon energy range 0.79 to $1.5 \mathrm{gev}$ was found to be $6 \neq 2 \mathrm{mb}$. For the nucleon-deuteron interaction near 1 Bev, the three wave functione above ylelded correction factera of 5.7, 7.2, and $4.5 \mathrm{mb}$ respectively. 14 Experimentally, the correction was found to be $7.4 \mathrm{mb}$. Thue for the particular casee mentioned the Gauber correction seeme adequate. 
Considerations of the same corrections in the circumetance where the incident particle is an antiproton result in extremely large ahadow factors. This is because of the large size of the $\bar{p}-p$ (and preaumably the $\bar{p}-a$ ) crose vectlone in relation to the nucleon-nucleon cross section. The validity of the approximate Glauber formulas (Eqa. 23, 24) is in serious doubt, especially in view of the asoumption that the radius of interaction is mnch omaller than the alse of the deuteron.

I. S. Blair has calculated the shadow effect by meane of a remiclasalcal model which does not require this last assumption. 45 it is therefore certainly more appropriate in the antinucleon cass. For mall values of the freo-nucleon crose ectione, the Blair Calculation. yidd the same result as the approximate Glauber factors, and hence the sume agreement for the $\overline{m-d}$ and $p^{+}-d$ croes sectlone mentioned in the previous paragraphs. The disagreement with the approxdmate Glauber formula becomes atrongly apparent when the free-nucleon crose sectlons are $60 \mathrm{mb}$ or greater, as in the case of antinucleons. The Blair calculations rent principally on the assumptions that the impulse approximation is valld, and that the interaction can be represented by a black disc. These calculations were made in anticipation of $\vec{p}-d$ cross seations such as ours.

In Table VI, the Blair correction factoro, $C_{1}$, for the inelactic or abeorption cress sections are thown. The model for the deuteron ueed was the Hulthen weve function

$$
\psi_{d}=\left[\frac{a}{2 \pi} \frac{\beta(a+\beta)}{(a-\beta)^{2}}\right]^{1 / 2} \frac{\exp \mid-a x]-\exp \mid-\beta z]}{r} .
$$

with $\beta=6 a$, whero $\beta=3 / p\left(1+\frac{4}{9} a\right)^{-1}$, correoponding to a triplet effective range $=1.75 \times 10^{-13} \mathrm{~cm}$. In the second column of the table we have the apperent neutron cross section " $\sigma(p-n)$ " defined by the direct aubtraction $\sigma(\bar{p}-d)-\sigma(\bar{p}-p)$, from the data of Tables III and V. The true or corrected neutron crose sectlens are shown in the final column. 
The correction factors for the total or elantic cross sections morit additlonal consideration. Shielding of the abeorption cross section is more easily understood because absorptive proceses by the two nucleons are mutually axclusive events. In the total cross wection other factor are involved, ouch as interference affecte, double ecattering, and scattering by one nucleon followed by absorpclon by the ather. It is shown by Glauber ${ }^{42,46}$ that all these effecte are taken into account by his general correction formula for $\sigma_{t}, "$ " of which Eq. (23) is an approximation. The dfference between the formula for the total cross section Eq. (23) and the one tor the absorption cross section (Eq. 24) is eimply a factor of 2. This difference is valid only for a purely absorptive interaction; however, it is independent of the opacity of the interaction region. In view of the uee of the optical theorem in conjunction with the last as sumption to obtain Eq. (23), the reoulting correction to the total cross section should be a minimum correction. We therafore amploy this factor of 2 together with the more explicit Bladr resulte to obtain the total-crosssection correction whown in Table VI. The elastic $\bar{p}-n$ cross section was obtained by subtracting $\sigma_{1}$ from $\sigma_{t^{*}}$ The resulte are plotted in Fig. 16 for a comparison with the $\bar{p}-p$ values.

\section{Conclueton:}

From the presentation in Fig. 16 it is ceen that the $\bar{p}-n$ and the $\bar{p}-p$ crose ections are otatiotically the same within the energy interval of this experiment. It should be emphasised that this conclusion rest on the valldity of the Blalr correction factore employed to obtain the $\bar{p}-n$ crose sections. These correction factore have not been experimentally proven for antinucleon cross sectione as they have been for nucleon and pion crose sections. In view of the asumptions made in the derivatione of the ahielding factors, 42,45 they are not expected to be entirely 
accurate, but to provide a reasonable estimate. The badow correction to the annihilation cross sections seems the most rellable, because fewer asumptione are involved. The other shadow corrections would ceem to be more uncertain bocause of the assumption of a purely absorptive interaction with zero phase shift.

The equality of $\bar{p}-p$ and $\bar{p}-n$ croms sections may not be totally unexpected. The near equality is noted in the calculations by Ball and Fulco for antinucleons in the energy range 50 to $250 \mathrm{Mev}$. 47 Their theoretical reeulte are based on the theory of gall and Ghew. ${ }^{10}$ As the low-energy experimental results for the $\bar{p}$-p cross sections support the theoretical expectations, it would not be surprising for the $\bar{p}-n$ cros sections to do likewiee, although no expeximental $\bar{p}-n$ information exiote at low energles.

The $\bar{p}-p$ syetem may interact through the isotopic epin states $I=0$ and $I=1$ with equal probability. The $\bar{p}-n$, howerer, exiete only in the $I=1$ state. Thus within the limits of our errors, the equality of the $\bar{p}-n$ and $\bar{p}-p$ crose sections reveale that the antinucleon-nucleon Interaction occure in the $I$ = 0 and $I$ = 1 states with the same probability. There exiet inequality relations between $\bar{p}-p$ and $\bar{p}-n$ cross sectione which are independent of detalled nuclear models and require only the charge independence of nuclear forces. These inequalitien follow from the fundamental relations of the cattering amplitudes between initial and final states of $T=0$ and $T=1$. The resulting exprensions, which have been summarized in Reference 48, are as follows: 


$$
\begin{aligned}
& \frac{d \sigma_{c}(\bar{p}-p)}{d n}\left(0^{\circ}\right) \geqslant(k / 4 \pi)^{2}\left[\sigma_{t}(\bar{p}-n)-\sigma_{t}(\bar{p}-p)\right]^{2} \\
& \sigma_{e}(\bar{p}-p)+\sigma_{c}(\bar{p}-p)>1 / 2 \sigma_{e}(\bar{p}-n) \\
& \mid\left(\sigma_{c}(\bar{p}-p)\right\}^{1 / 2}-\left\{\left.\sigma_{e}(\bar{p}-n)\right|^{1 / 2} \mid \leqslant\left\{\sigma_{e}(\bar{p}-p)\right\}^{1 / 2} \leqslant\left\{\sigma_{c}(\bar{p}-p)\right\}^{1 / 2}+\left\{\sigma_{e}(\bar{p}-n)\right\}^{1 / 2} .\right. \\
& \left|\left\{\sigma_{c}(\bar{p}-p)\right\}^{1 / 2}-\left\{\sigma_{e}(\bar{p}-p)\right\}^{1 / 2}\right| \leqslant\left\{\sigma_{e}(\bar{p}-n)\right\}^{1 / 2} \leqslant\left\{\sigma_{c}(\bar{p}-p)\right\}^{1 / 2}+\left\{\sigma_{e}(\bar{p}=p)\right\}^{1 / 2} . \\
& \mid\left\{\sigma_{e}(\bar{p}-n) s^{1 / 2}-\left\{\sigma_{e}(\bar{p}-p)\right\}^{1 / 2} \mid \leqslant\left(\sigma_{c}(\bar{p}-p)\right\}^{1 / 2} \leqslant\left(\sigma_{e}(\bar{p}-p)\right\}^{1 / 2}+\left(\sigma_{e}(\bar{p}-p)\right\}^{1 / 2} .\right.
\end{aligned}
$$

Relations (27) through (30) are sidufified by our data of Fig. 16. The first relation (Fq. 26) is satisfied by our value for $\sigma_{t}$ (at $948 \mathrm{Mev}$ ) and a value $4.6 \mathrm{mb} / \mathrm{er}$ for the differential charge-exchange cross section obtained by Finrichs. 31 The antinucleon-nucleon data are therefore conslatent with the relation required by charge independence in the energy range 500 to $110 \mathrm{Mev}$. For this relatively low energy range the data is also in accordance with the theorem of Pomeranchuk which states that the $\bar{p}-p$ and the $\bar{p}-n$ cross sections should become equal te stixth energles' as a consequence of conservation of isotopic spin. $49, \ldots, \ldots$ An additional theorem due to Fomeranchuk, based on the disperafon relation for elastic acattering of nucleons in the forward direction, sates that the $\bar{p}-p$ and the p-p crose sectione should also be the same at 'high energies. 50 At the energies under investigation here and in those of reference 24 , the $\bar{p}-p$ cross sections remain much larger than the p-p cross sections. Recent crose-section measuremente up to $20 \mathrm{Bev} / \mathrm{c}$ how larger $\overline{\mathrm{p}}-\mathrm{p}$ crose sections; 51,52 bowever, the $\bar{p}-\mathrm{p}$ and $\mathrm{p}-\mathrm{p}$ total croes sections seem to be approaching each other at higher energtes. 
$-36$.

UCRL- 9288 Rev.

ACKNOWLEDGMENTS

We with to thank Professor Emilio Segre for his support and advice, and Dr. Norman Booth for his aid in the successful operation of the experiment. The assistance of Mr. Bull Johnson and Mr. Olav VI was appreciated. Mr. Don Bliss and the Accelerator Technicians constructed a great deal of the experimental apparatus. The task of scanning the oscilloscope film was enthusiastically performed by Mr. L. Auerbach, Mr. F. Bacastow, Dr. Jim Tote, Mr. J. Lack, Mr. E. Rogers, and Mr. H. Rage. Additional holp wee given by Mise Maureen Kano, Mr. K. Nataini, Miss Jean Fry, Mas Francis Wilcox, and Mr. R. Talema. Finally we wish to thank the Bevatron personnel for their support and cooperation during the experiment. 
REFERENCES

*Now at Los Alamos Scbentific Laboratory.

1. T. Elloff, L. Agnew, O. Chamberlain, H. M. Steinex, O. Wiegand, and

T. Ypailantis, Fyse. Rev. Lettere 3, 285, (1959).

2. O. Chamberlain, in Proceedinge of the 1960 Annual Internntion Conference on High-Energy Phyeles at Rocheoter, Auguet 25-September 1 edited by E. C. G. Suderoban et al. (Intersclence Publisherm, Inc. . New York, 1960), p. 653 .

3. W. A. Wenrel, in Froceedinge of the 1960 Annual International Conference on High-Energy Phyclce at Rochester. Auguat 25-September 1. (Intereclence Publishere, Inc. New York, 1960), P. 151.

4. Coombes, B. Cork, W. Calbraith, G. Lamberteon, and W. A. Wenzel, Phys. Rev. 112, $1303(1958)$.

5. L. Agnew, T. Ellof, W. Fowlex, R. Lander, W. Powell, E. Segrd, H. M. Steiner, H. White C. Wlegand, and T. Ypoilantia, Fhys. Rev. 118. $1371(1960)$.

6. N. Horwts, D. Millex, J. Murray, and R. Tripp, Phyd. Rev. 115, 472 (1959).

7. G. Coldhaber, S. Coldhaber, W. Powell, and R. Silberborg, Phys. Rev. 121, 1525 (1961).

8. O. Chamberlain, D. Keller, R. Mermod, E. Segre, H. Stelner, and T. Ypollantie, Phya. Rev. 108, 1553 (1957).

9. B. Cork, G. Lemberteon, O. Plccionl, and W. Wenzel, Phys. Rer. 107, 248 (1957).

10. J. Ball and G. Chew, Phys. Rev. 109, 1385 (1958).

11. Z. Kobe and G. Takeda, Progx. Theoret. Phye. (Kyoto) 19. 269 (1958).

12. L. Agnew, O. Chamberlain, D. Koller, R. Mermod, E. Rogers, H. Stelner. and C. Wiegand, Fhya. Rov. 108, 1550 (2957). 
13. O. Chamberlain, D. Kellex, E. Segrd, H. Stelner, and C. Wiegand, Fhya. Rer. 102. $1637(1956)$.

14. Owen Chamberlain, Ann. Rev. Nuclear Sci. 10. 161 (1960).

15. Harold Ticho, Proceedings of the International Conference on High-Energy Accelerators and Instrumentation, CERN 1959 (CERN Scientific Informatlon Setraice, Genera, 1959), p. 390.

16. H. G. Jackson, D. A. Mack, and C. Wiegand, IRE, Trans. on Nuclear Sctence NS-6, 64 (1959).

17. O. Chamberlain and $C$. Wiogand, Proceedinge of the CERN Symposium on High-Energy Acceleratore and Plon Physics, Vol. II (CERN Sclentific Information Service, Ceneva, 1956), p. 82.

18. Edwin McMillan, Rev. Sci Instr. 22, 117 (1951).

19. O. Chamberlain, W. Chupp, G. Coldhaber, E. Segrt, C. Wiegand. E. Amaldi, G. Baronl, C. Castagnoli, C. Fransinettl, and A. Menfredinl, Nuovo cimento 3,462 (1956).

20. R. Hagedorn. Nrovo cimento 15, 246 (1960).

21. O. Chamberlain, L. Segre, C. Wiegand, and T. Ypptanta, Phys. Kev. 100, 947 (1955).

22. V. Cocconi, T. Eazzini, G. Hidecaro, M. Legron, N. Lipman, A. Merrieon, Phya. Rev. Letter 5. 19 (1960).

23. L. Gilly, B. Leontic, A. Lundby, E. Meunier, J. Stroot, and K. Sseptyckn, Proceedinge of the 1960 Annual International Conference on High-Linerry

Physics at Rochester(Interscience Publishera, Now York. 1960), p. 808.

24. F. Armenteros, C. Coombee, B. Cork, G. Lambertean, and W. Wenzel, Phys. Rev. 119. 2068 (1960).

25. S. Fernbach, R. Serber, and T. B. Taylor, Phys. Rev. 75, 1352 (1949).

26. F. Solmitz. Proceedinge of the 1960 Annunl International Conference on HighEnergy Physice at Rochester, (Interocience Publichers, New York, Nowy. 168. 
27. N. Xuong, G. Lynch, C.K. Hinxichs, Phys. Rov. 124, 575 (1961).

28. W. Rartia, Phys. Rov. 104, 222 (1956).

29. J. Lannutti, G. Lynch, 3. Maglic, M. L. Stevencon, and N. Xuong, Proceedings of the 1960 Annual International Conference on High-Enorgy Physice at Fochester (Interecience Publiwhers, New York), p. 160.

30. Bipin K, Desal. Fhya. Kev. 119, 1390 (1960).

31. C. Keith Hinrichs, Charge-Fxchange Production of Anfinategens, Lawrence Eadiation Laboratory Report UCRL-9589. March 1961 (unpublished).

32. G. Baront, C. Belletint, C. Cantagnoll, M. Ferro-Lumat, and A. Manfredinl, Nuovo cimento 12, 564 (1959).

33. J. Eutton, T. Flioff, E. Segre, H. Steiner, R. Wiengart, C. Wiegand, and T. Y peilantie, Phys. Rov. 108, 1557 (1957).

34. S. Gartenhaus, Phys. Rev. 107, 291 (1957).

35. P. Signell and R. Marahak, Phye. Rev. 109, 1229 (1958).

36. G. Chew, Proc. National Acad. Sci. U. S. 45, 456 (1958).

37. D. Yennie, M. Levy, and D. Revenhall, Keve. Modern Phys. 29, 144 (1957).

38. Geoffrey Chew, in Proceedinge of the 1958 International Conference on HighEnergy Physics at CERN, edited by Serretti, (CF:N Scientifle Intormation Service, Geneva, 1958), p. 106.

39. F. Temm, Soviet Physics JETP 5, 154 (1957).

40. Burton J. Moyer, in Physics Division Semiannual Feport, Aug. 1959, Lawrence Fadiation Laboratory Feport UCF L-8936 (unpublished), p. 33. 41. Meshcheriakov, Bogachev, Leksin, Naganov, and Piskarev, in Proceedinge of the CERN Symposium on Figh-Energy Acceleratore and Plon Phyolce, Vol. II (CERN Scientific Information Service Geneva, 1956), p. 124.

42. F. Glauber, Phys. Fev. 100, 242 (1955). 
43. R. Cool, O. Piccioni, and D. Claxk, Phys. Rev. 103, 1082 (1956).

44. F. Chen, C. Leavitt, and A. Shapiro, Phyu. Rev, 103, 211 (1956).

45. J.S. Blair, Nuclear Fhy". 6, 348 (1958).

46. R. Glauber, Lectures in Theoretical Pbyeics (Interacience Publiabera, New jork, 1959 , p. 378 .

47. J. Ball and J. Fulco, Phys. Fiev, 113, 647 (1959).

48. T.. Segrè, Annual Rev. Nuclear Sci. 8, 127 (1958).

49. I. Pomeranchuk, Soviet Physics JETP 3, 306 (1956).

50. I. Pomeranchuk, Soviet Physics JEIP ? 499 (1958).

51. G. von Daxdel, D. Ërish, E. Mermod, E. Mílburn, P. Firoue, M. Vivargent, G. Weber, and K. Winter, Phys. Rev. Letters 5, 333 (1960).

52. S. Lindenbaurn, W. Love, J. Niederex, S. Ozaki, J. Russel, L. Yuan Phys. Bev. Letters 7, 184 (1961). 
Table 1. Experimental component: of $\mathrm{Mg} \cdot 1$.

Symbol

Component description

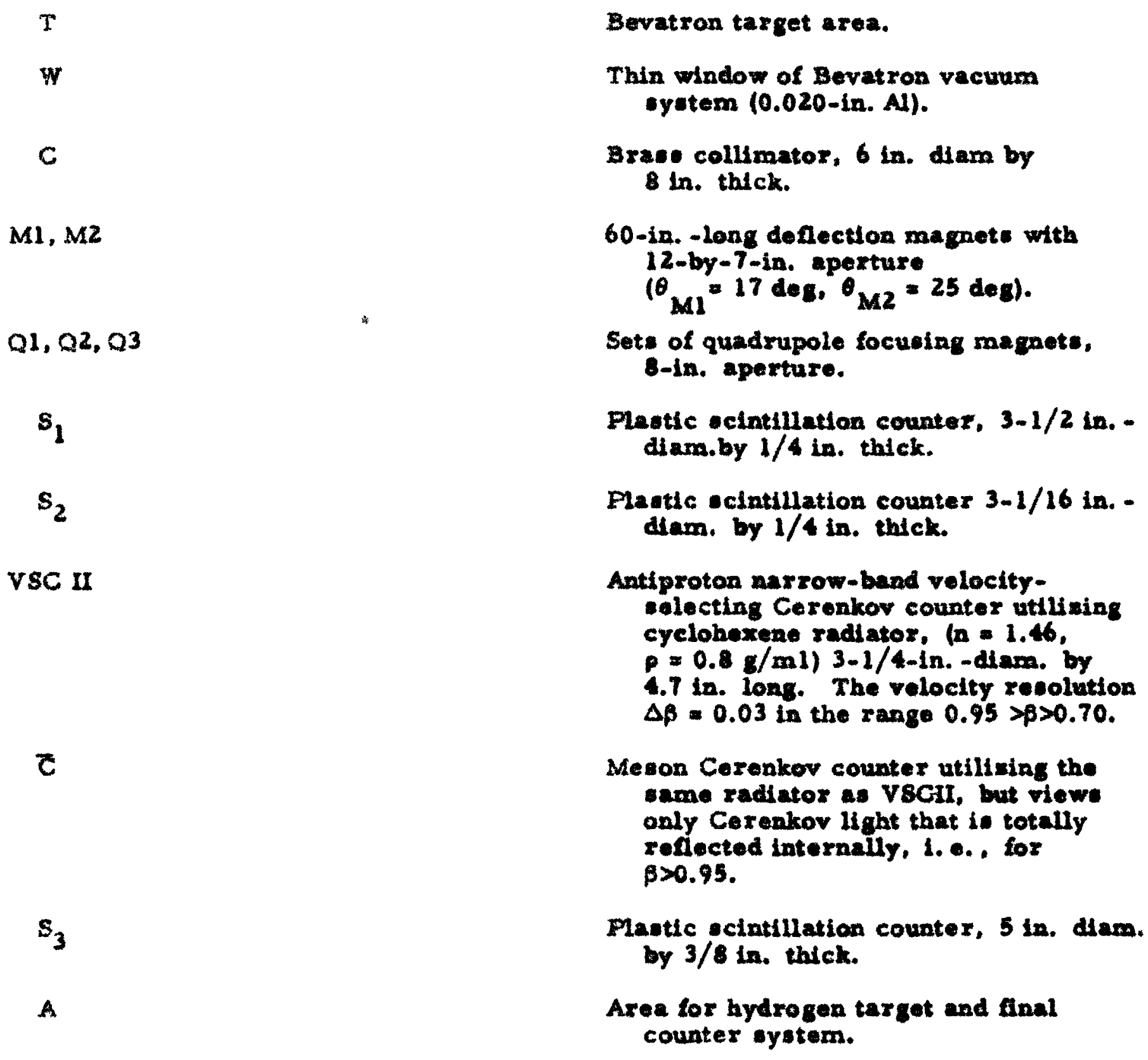


Table 11. Production of antiprotone of various momenta by 6-Bev protons.

\begin{tabular}{|c|c|c|c|c|c|c|}
\hline $\begin{array}{l}\text { Momentum } \\
(\mathrm{Mev} / \mathrm{c})\end{array}$ & $\begin{array}{l}\text { Angle of } \\
\text { emierioa } \\
\text { (deg)(1ab) }\end{array}$ & $\begin{array}{l}\text { Taxget } \\
\text { length } \\
\text { (cm) }\end{array}$ & $\begin{array}{r}\text { Target } \\
\text { material }\end{array}$ & $\begin{array}{l}-1 p^{+2} \\
\left(10^{-7}\right)^{2}\end{array}$ & $\begin{array}{l}5 / \pi^{-a} \\
\left(10^{-5}\right)\end{array}$ & $\underset{\bar{p} / p^{+}}{\left(10^{-11}\right)}$ \\
\hline 1200 & 5 & 5.08 & carbon & 12.0 & $1.8 \pm 0.1$ & $13.8 * 0.8^{c}$ \\
\hline 1400 & 3 & 5.08 & carbon & 11.2 & $2.9 * 0.2$ & $22.1 \neq 1.5^{c}$ \\
\hline 1531 & 1.5 & 5.08 & carbon & 11.8 & $3.5=0.3$ & $34.7 \pm 2.1^{c}$ \\
\hline 1684 & 0 & 5.08 & carbon & 11.8 & $3.8 \pm 0.2$ & $39.2 \pm 1.6^{c}$ \\
\hline 1825 & 1.5 & 5.08 & carbon & 11.9 & $3.6+0.3$ & $37.4 \pm 2.2^{c}$ \\
\hline 1700 & 0 & 15.3 & beryllium & 13.0 & $4.5 \pm 0.5^{d}$ & \\
\hline 2000 & 0 & 15.3 & beryllium & 12.0 & $4.8 \pm 0.5^{\mathrm{d}}$ & \\
\hline 2800 & 0 & 15.3 & bexyllium & 9.0 & $2.9 * 0.9^{d}$ & \\
\hline 750 & 8.5 & 15.3 & beryllium & 8.0 & $0.2 \approx 0.12^{3}$ & \\
\hline 900 & 3 & 15.3 & beryllium & 12.0 & $0.4 \pm 0.24^{\circ}$ & \\
\hline 1150 & 2.5 & 15.3 & beryllitum & 20.0 & $1.2 * 0.7^{\circ}$ & \\
\hline 1410 & 6.2 & 15.3 & beryllinm & 22.0 & $1.9 \pm 1.11$ & \\
\hline 600 & 0 & 15.3 & beryllinm & 40. & $0.15=0.07^{f}$ & \\
\hline 700 & 0 & 15.3 & beryllium & so. & $0.2440 .12^{1}$ & \\
\hline 800 & $\mathbf{0}$ & 15.3 & beryllium & 50. & $0.44+0.22^{f}$ & \\
\hline 900 & 7 & 15.3 & bexyllinm & & $0.80 \times 0.10^{2}$ & \\
\hline \multicolumn{3}{|c|}{$\begin{array}{l}\text { Aranemitted through magnetic channel. } \\
\text { borrected at carbon target. }\end{array}$} & \multicolumn{2}{|c|}{$\begin{array}{l}\text { CThis experimeat. } \\
\text { d Reference } 24 .\end{array}$} & \multicolumn{2}{|c|}{$\begin{array}{l}\text { Beference } 9 . \\
\text { Feference } 4\end{array}$} \\
\hline
\end{tabular}


Table II. $\bar{p}-p$ crose section at varions energles.

\begin{tabular}{|c|c|c|c|c|}
\hline \multirow[b]{2}{*}{$\begin{array}{c}\overline{\mathbf{P}} \text { energy } \\
\text { (Mer) }\end{array}$} & \multicolumn{4}{|c|}{ Cross sections (mb) } \\
\hline & Total & Elastic & InelantIc & Charge-exchange \\
\hline $534 * 25$ & $118+6$ & $42 \pm 5$ & $70 \neq 3$ & $6.0 \neq 1.3$ \\
\hline $700 \pm 33$ & $116 \pm 5$ & $42 \pm 4$ & $66: 3$ & $7.2 \pm 1.5$ \\
\hline $826: 37$ & $108 \pm 5$ & $38: 4$ & $63 \pm 3$ & $7.1 \pm 1.2$ \\
\hline $948+42$ & $96 \pm 3$ & $33 \pm 3$ & $56 \pm 2$ & $6.8 \pm 1.0$ \\
\hline $1068 \pm 46$ & $96 \pm 3$ & $30 \pm 2$ & $60 * 2$ & $5.7 \pm 1.1$ \\
\hline
\end{tabular}


Table IV. Optical-model parameters

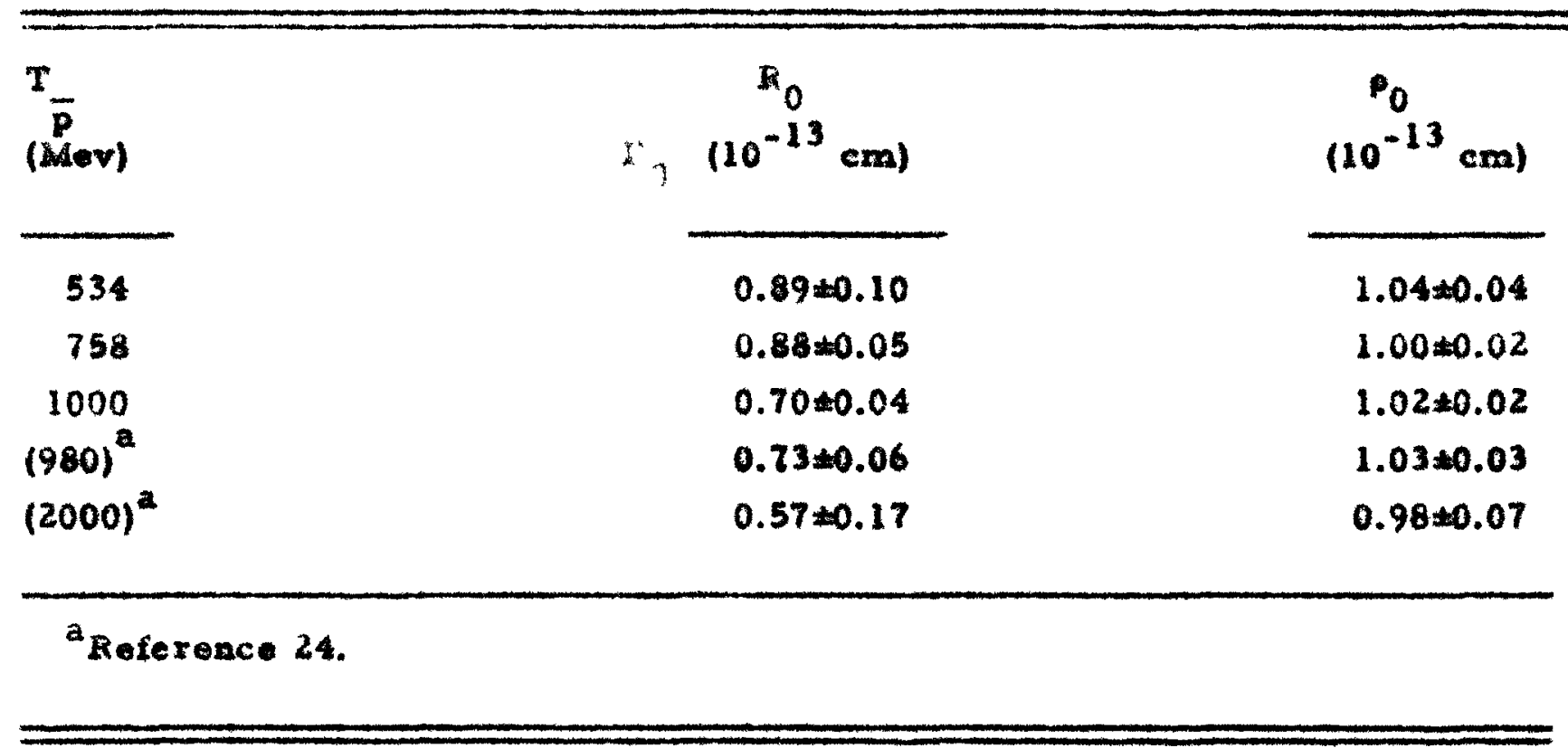


Table V. $\bar{p}-d$ cros sectlons (mb).

\begin{tabular}{|c|c|c|c|c|}
\hline$\frac{\mathfrak{f}}{p}$ & $\sigma_{1}$ & $\sigma_{0}$ & $\sigma_{i}$ & $\sigma_{c}$ \\
\hline \multicolumn{5}{|l|}{ (Mev) } \\
\hline 534 & $210 \star 5$ & $80 \pm 6$ & $126+5$ & $3.3 \pm 1.3$ \\
\hline 700 & $189 \neq 5$ & $67 \approx 5$ & $117 \pm 4$ & $5.4 \pm 1.4$ \\
\hline 816 & $196=6$ & $78 \pm 5$ & $112 \pm 4$ & $6.5 * 1.5$ \\
\hline 948 & $178 * 5$ & $71 \pm 5$ & $102 \pm 4$ & $4.4 \pm 1.1$ \\
\hline 1068 & $184 * 3$ & 6844 & $109 \pm 5$ & $5.6 \pm 1.0$ \\
\hline
\end{tabular}


Table VI. Evaluations of the $\bar{p}-n$ cros sectione (mb).

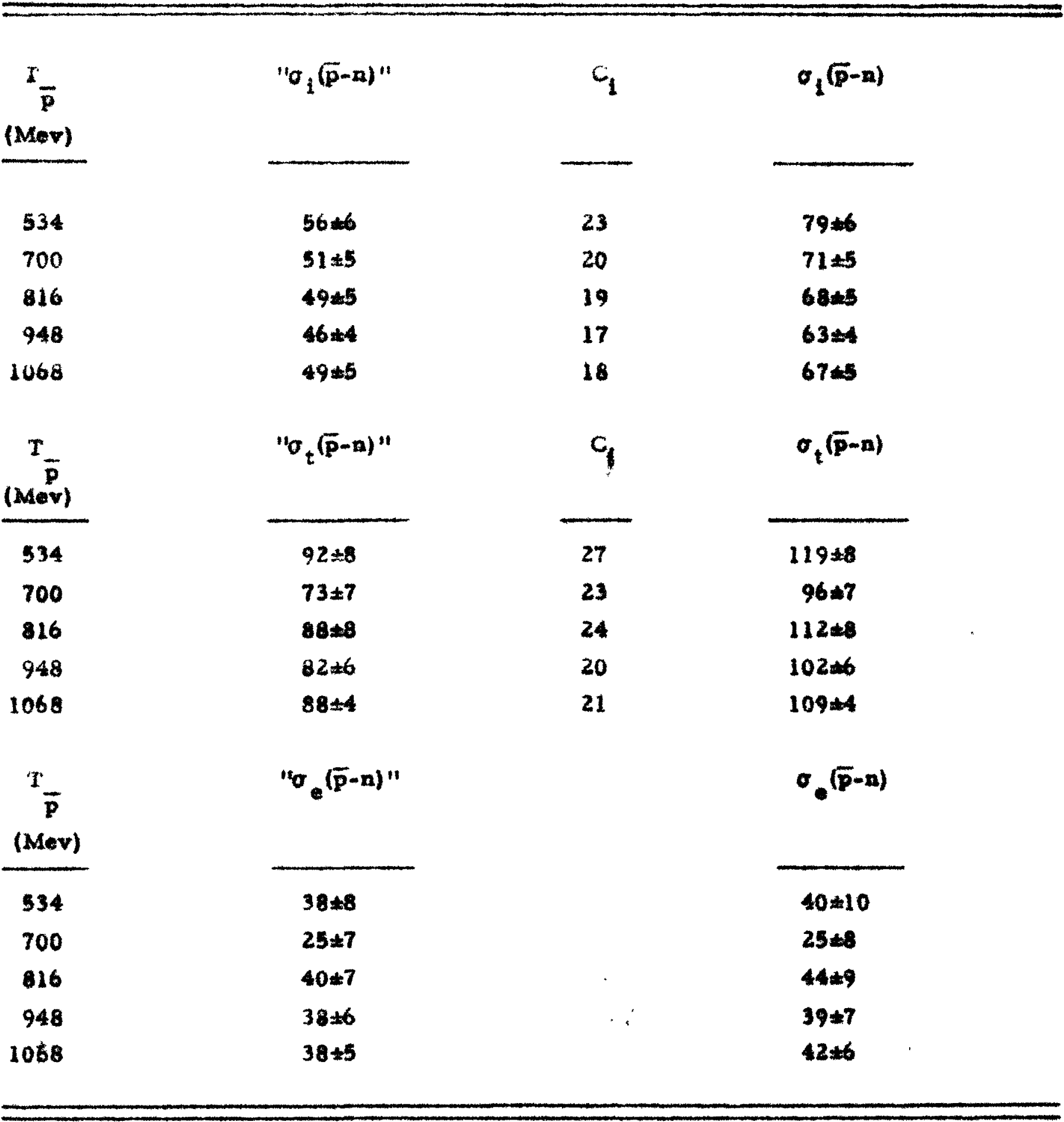


FIOUA LEGENDS

Mig. 1. Schematlc view of the Bevatron experimental area. Compenents are identified in Table 1 .

If. 2. Decilloscope photograph of beam-intenuty pattern behind the hydrogen target. Fach atep in the hotorgram represente $1 \mathrm{~cm}$ in the rertical plane.

Fg. 3. Schematic digram of the VSC-II and $\mathrm{C}$ countera.

Ig. 4. Efficiency and resolution of the rolocity-meleeting Cerroker eounter VSC-II for $\bar{p}$ momenta of 1200 and 1640 Mev/c (indicated by the arrown).

FI. 5. Side view of target-counter oydetem. For clartiy, the Agure is not shown to exact ecale. Container (A) could be alled with liquid hydregen or deuterium and in atainled ateel cylinder 12 in. long by $6 \mathrm{In}$, diam with $0.008-i n$. walle, except for the 0.010-in. Myler entrance wall. Grteen sciatillation covatere, S-1 through S-16, ourround contalner (A) cylladrically. The lead between the target and ecintllator: it removable. Heat shield (C) is 0.003-in. coppex; a thin region (3) of the vecuun wall is 0.035-in. aluminum.

Fig. 6. Schematic view from the beam-exit ond of the counter protem. Fis. 7. Simplified block alagram of the basic electronice.

IIg. 8. (a) Pootion of all postible pulaes on onclloucope Alm.

(b) Actud photo of fre ovente. All fre axe seen to have pulies $s_{1}, s_{2}, s_{3}$,

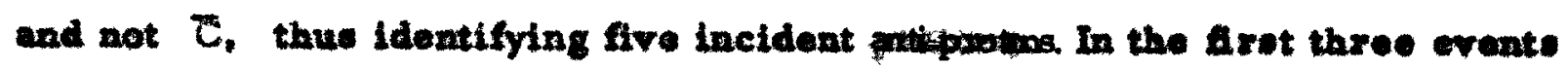
ouly counters $s_{4}$ or $8_{5}$, or both, wignal, meaning that the antiproton ald not Interact. In the fourth ovent the antipreton amililated, endiag plens into counter: $83,84,810$, and $\$ 15$. In the last eveat only a aingle count is detected in 81, which is typical of an eleotic scattering inte that comter. 
Fig. 9. Excitation function for $1684-\mathrm{Mev} / \mathrm{C}$ antiprotons produced at 0 deg in carbon. The curves aze taken from a statiotical model.

Fig. 10. Mementum dietribution for antiprotoas produced by approx 6-Bev protone on carbon and beryllium. The experimental point: are taken from Table 11 . The curve is calculated by a statiotical model.

Fig. 11. Angular dietribution of $\bar{p}-p$ clestic acattering at 534 Mev.

Ig. 12. Angular diatribution of $\bar{p}-p$ elabtic ecattering at 700 and $816 \mathrm{Mev}$.

Wg. 13. Angular dietribution of F-p elatic acattering near 1 Ber. The 980-Mev point: are from Armenteros et al. (reference 24).

Fig. 14. Shown are $\bar{p}-p$ eross sections an a function of antiproton kinetic energy. The open ymbole are total crose sections; cloeed aymbole are inalastic cross sectione (for $T_{\bar{p}}<288$ Mev thoy are amaihilation crose sections); open symbole encircling a dot are lastic crose section; open symbols crosed by a vertical line at the bettom of the Agure are charge-exchange crose sectione. The variou types of symbols refer to different experimente; the references are correlated with the eymbols in the upper right corner of the figure.

Nig. 15. Energy dependence of $\bar{p}-d$ croes sections. Square eymbol indlcates a reoult from reference 8.

Ng. 16. Comparison of $\bar{p}-p$ and $\bar{p}-n$ crose sections in the energy range 450 to $1068 \mathrm{Mev}$. 


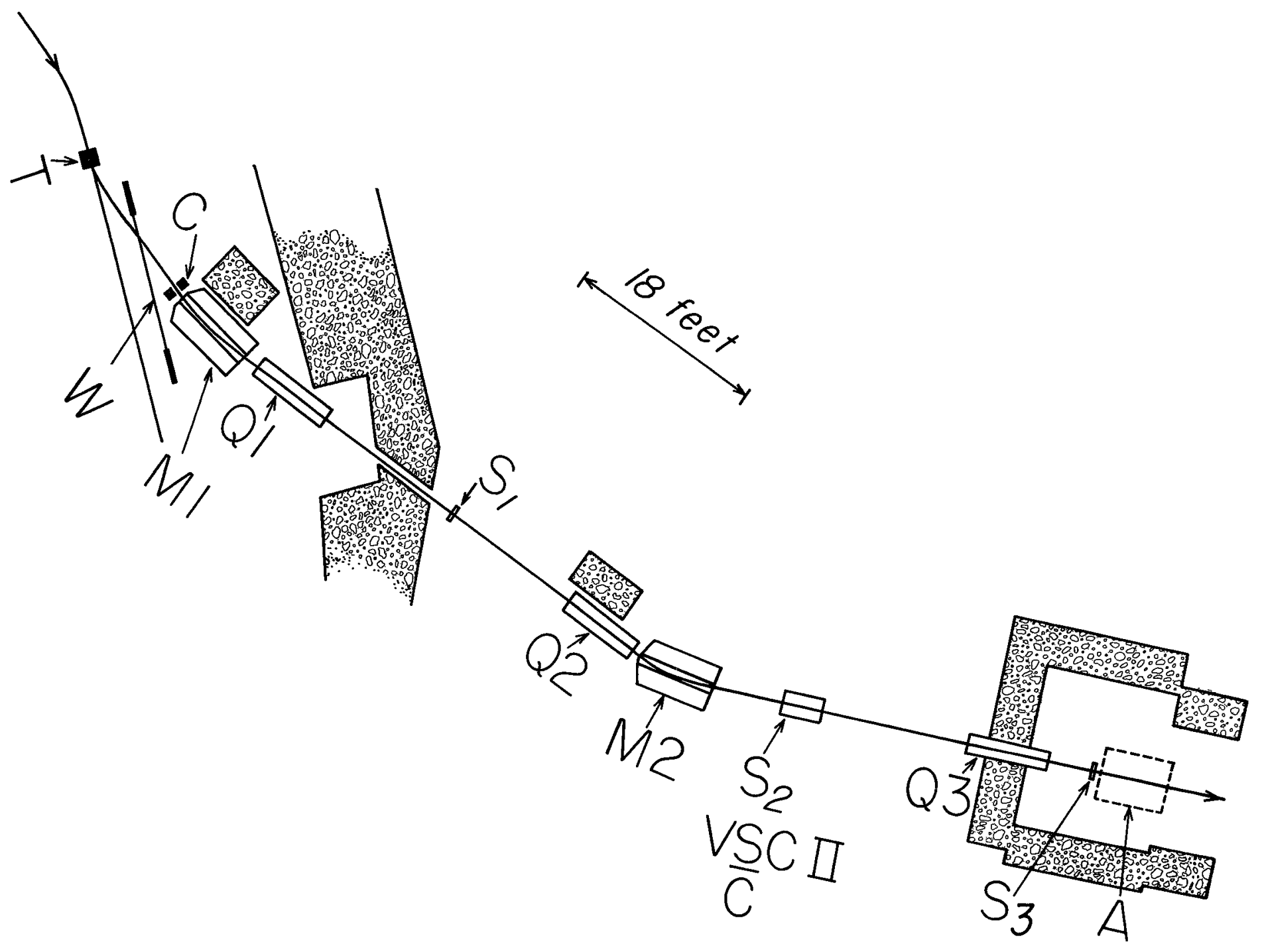




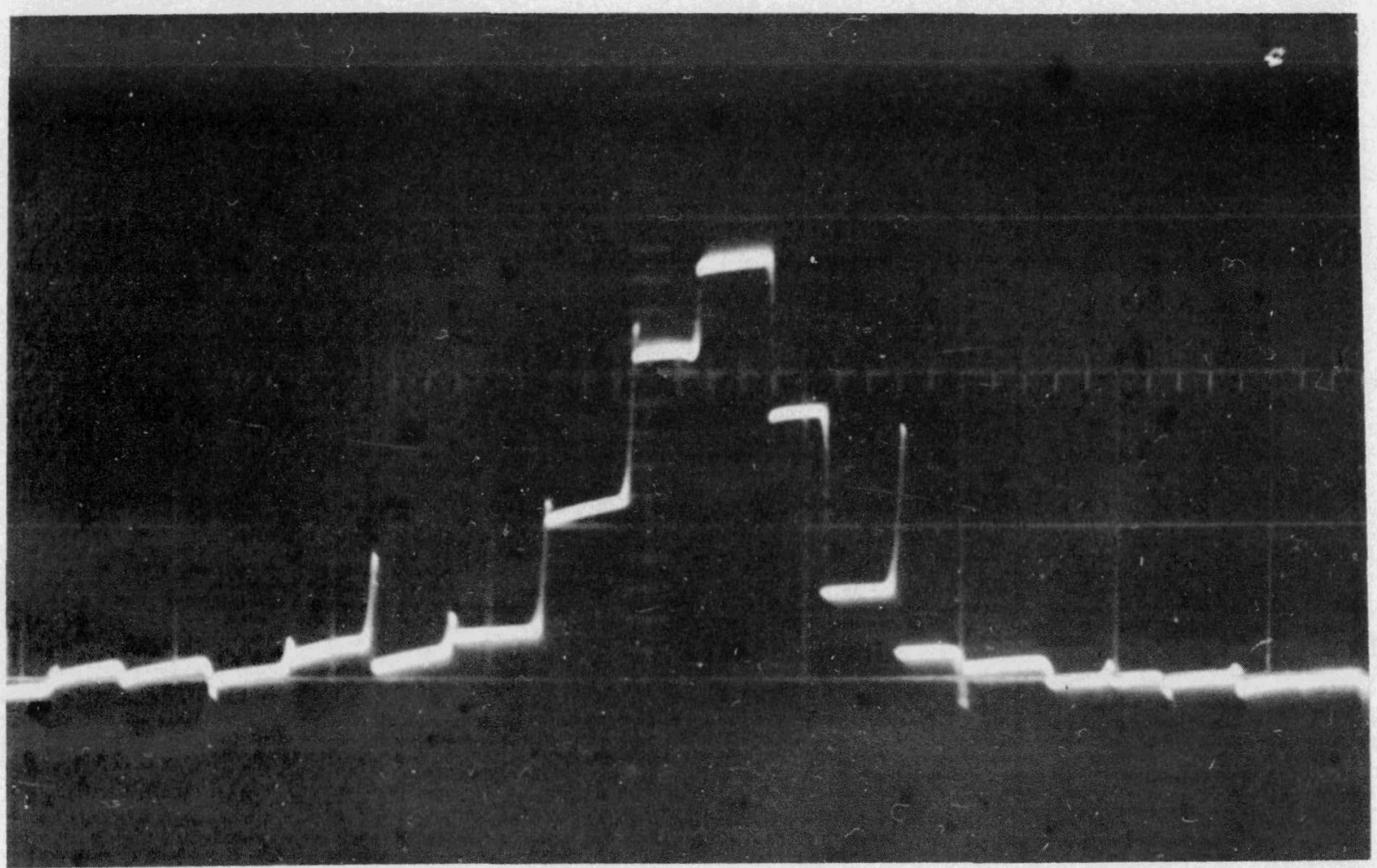

$\mathrm{ZN}-2553$

Fig. 2. Oscilloscope photograph of beam-intensity pattern behind the hydrogen target. Each step in the histogram represents $1 \mathrm{~cm}$ in the vertical plane. 

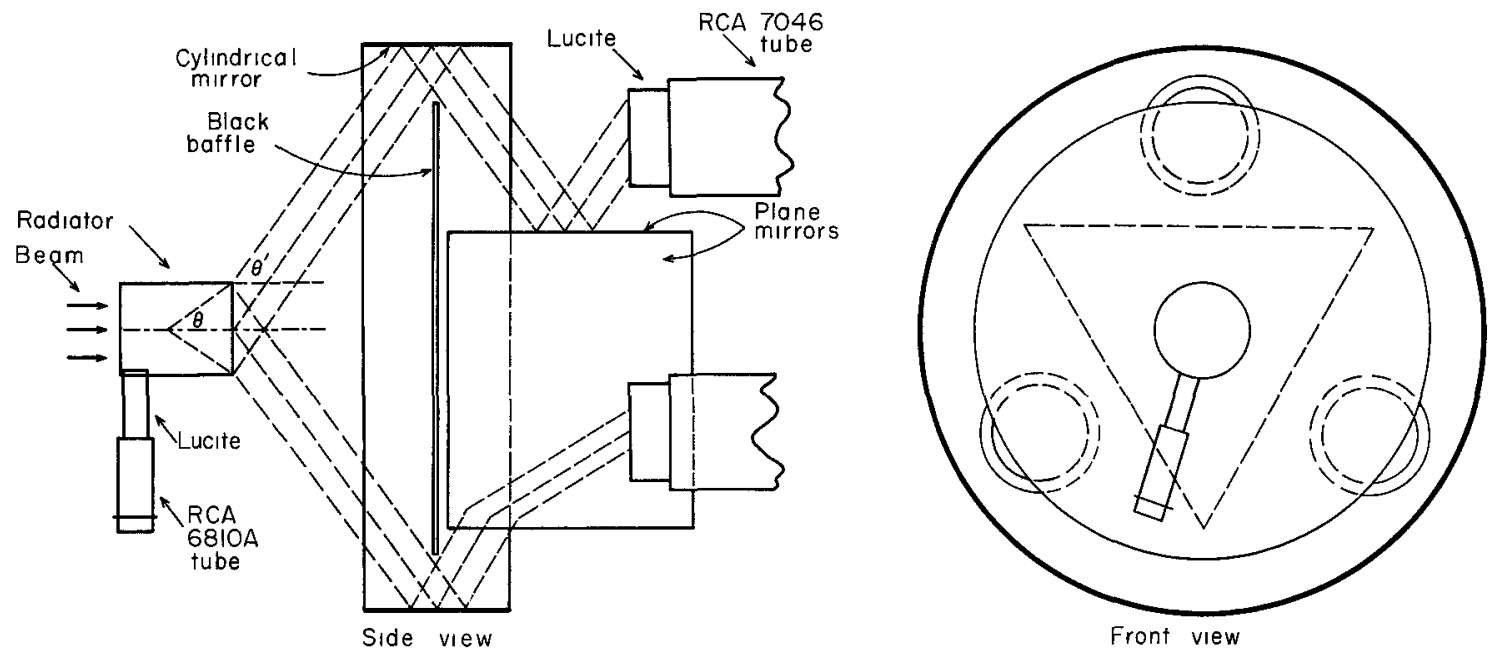

MU -20696

Fig. 3. Schematic diagram of the VSC-II and $\bar{C}$ counters. 


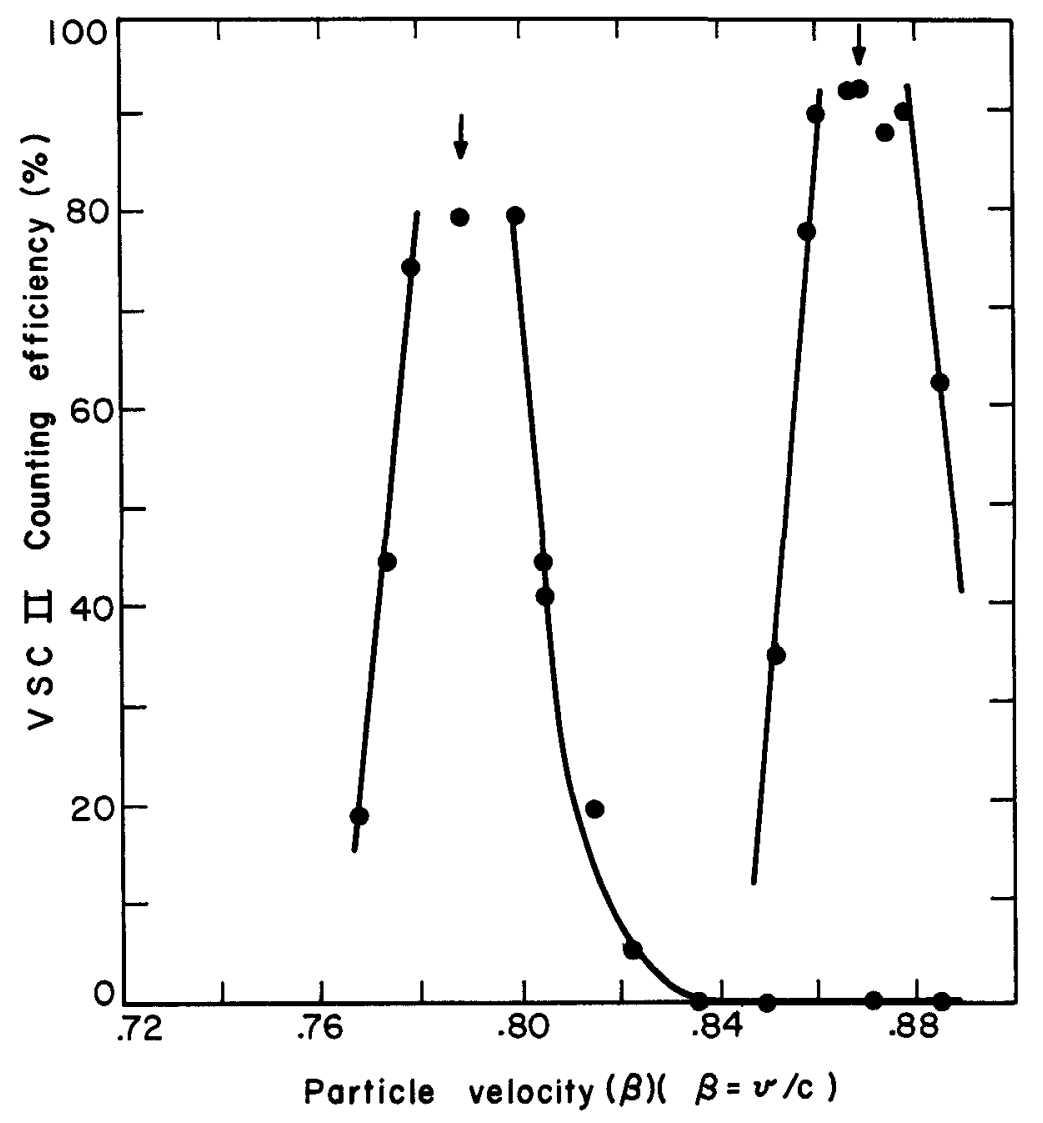

$M U-20697$

Fig. 4. Efficiency and resolution of the velocity-selecting Cerenkov counter VSC-II for $\bar{p}$ momenta of 1200 and $1640 \mathrm{Mev} / \mathrm{c}$ (indicated by the arrows). 


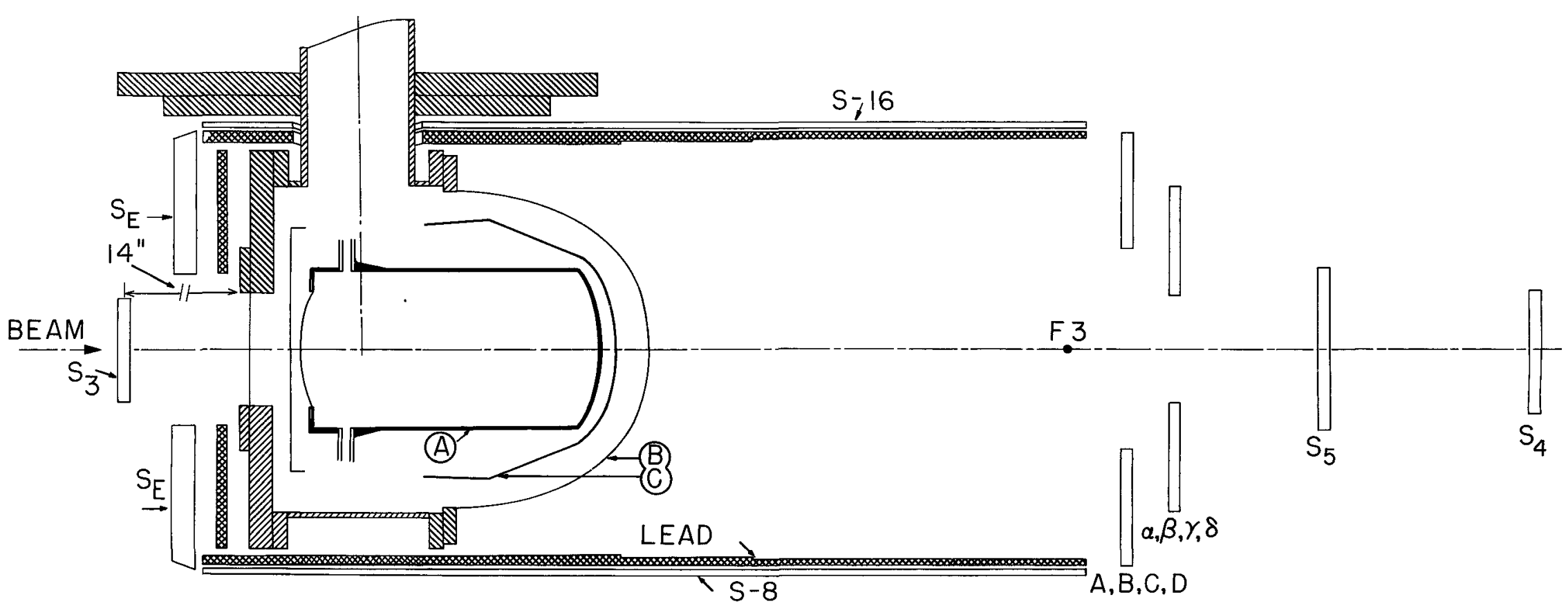

Fig. 5. Side view of target-counter system. For clarity, the figure is not shown to exact scale. Container (A) could be filled with liquid hydrogen or deuterium and is a stainless steel cylinder 12 in. long by 6 in. diam with 0.008-in. walls, except for the 0.010-in. Mylar entrance wall. Sixteen scintillation counters, S-l through S-16, surround container (A) cylindrically. The lead between the target and scintillators is removable. Heat shield C is 0.003 -in. copper; a thin region 'B' of the vacuum wall is 0.035 -in. aluminum. 


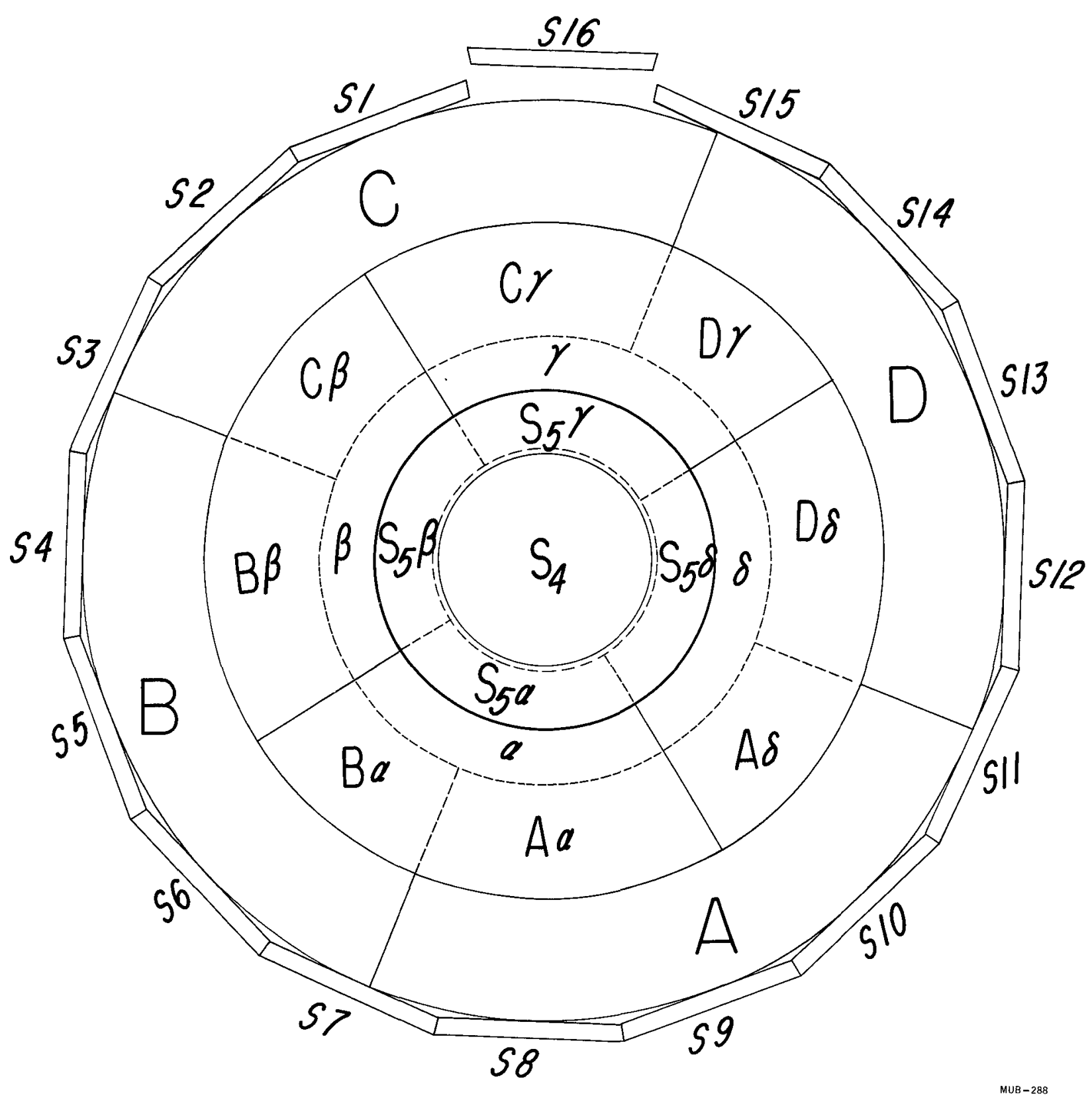

Fig. 6. Schematic view from the beam-exit end of the counter system. 


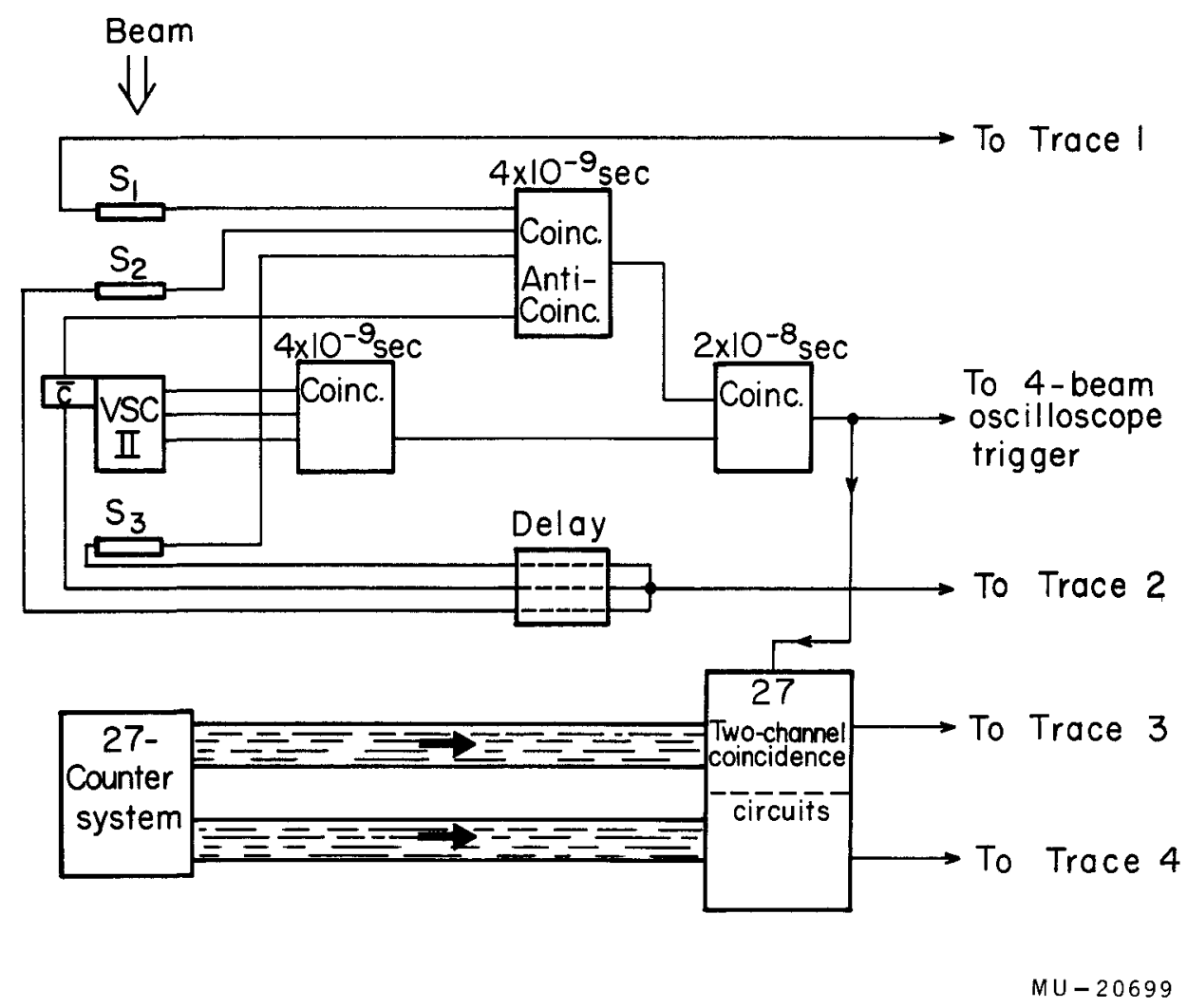

Fig. 7. Simplified block diagram of the basic electronics. 

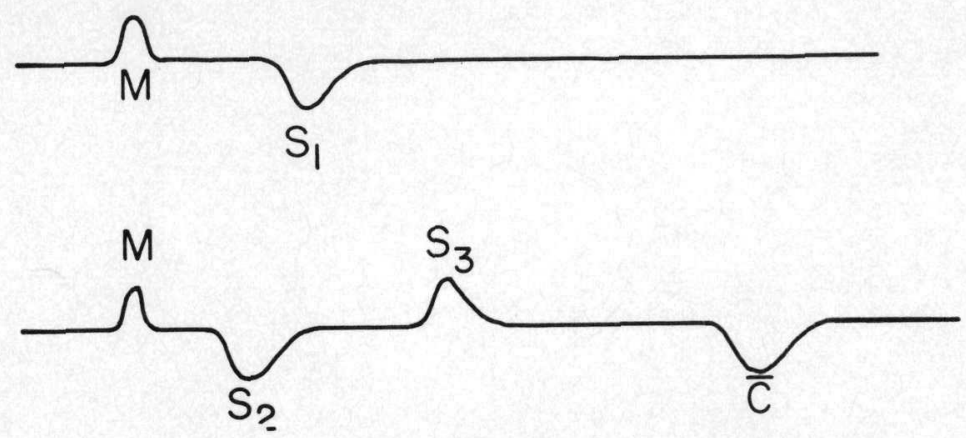

(a)
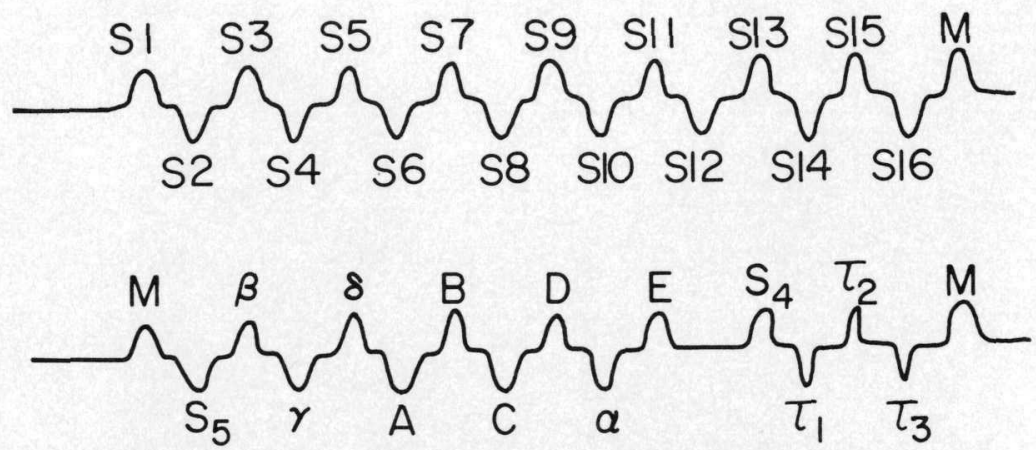

(b)

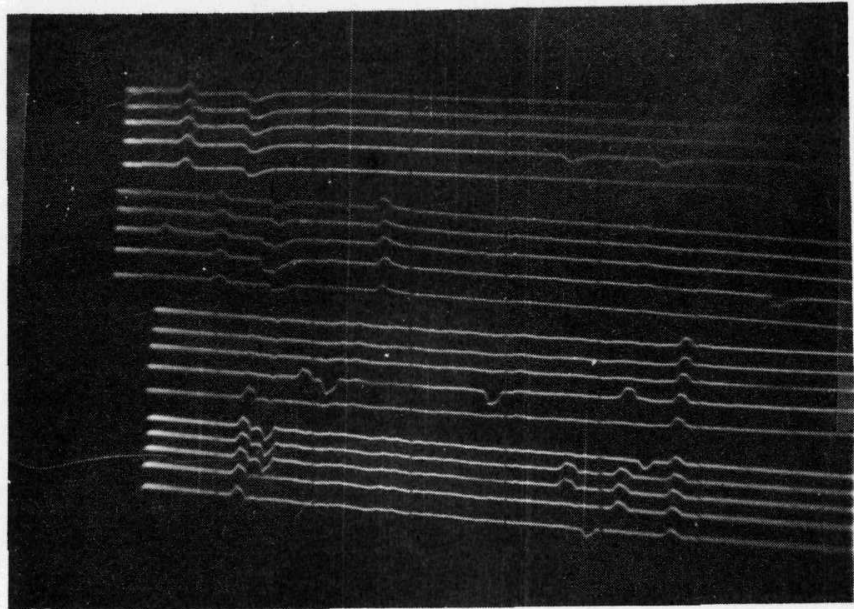

$\mathrm{ZN}-2555$

Fig. 8. (a) Position of all possible pulses on oscilloscope film.

(b) Actual photo of five events. All five are seen to have pulses $S_{1}, S_{2}, S_{3}$, and not $\bar{C}$, thus identifying five incident protons. In the first three events only counters $\mathrm{S}_{4}$ or $\mathrm{S}_{5}$, or both, signal, meaning that the antiproton did not interact. In the fourth event the antiproton annihilated, sending pions into counters $\mathrm{S} 3, \mathrm{~S} 4, \mathrm{~S} 10$, and S15. In the last event only a single count is detected in S1, which is typical of an elastic scattering into that counter. 


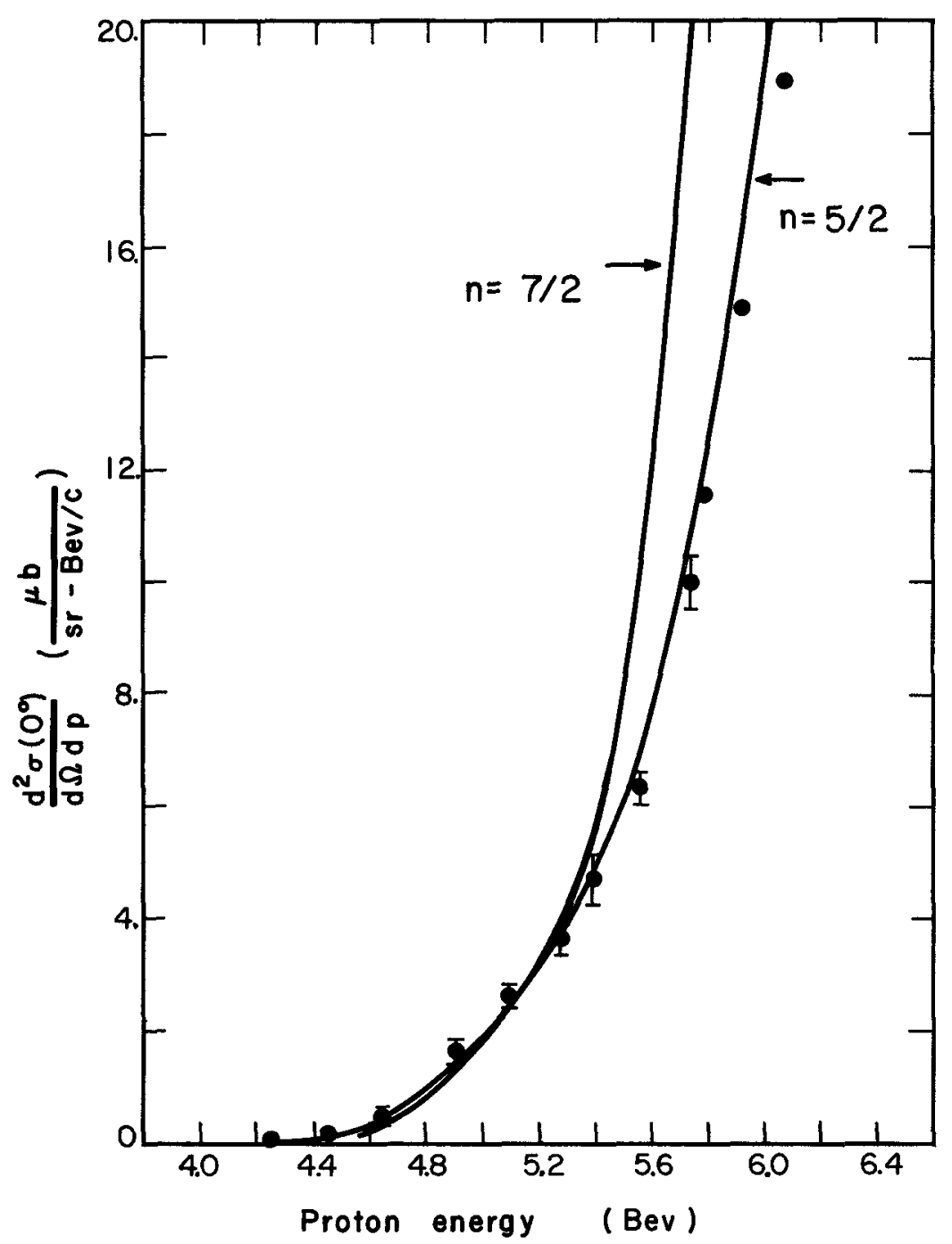

$M U-20701$

Fig. 9. Excitation function for $1684-\mathrm{Mev} / \mathrm{c}$ antiprotons produced at $0 \mathrm{deg}$ in carbon. The curves are taken from a statistical model. 


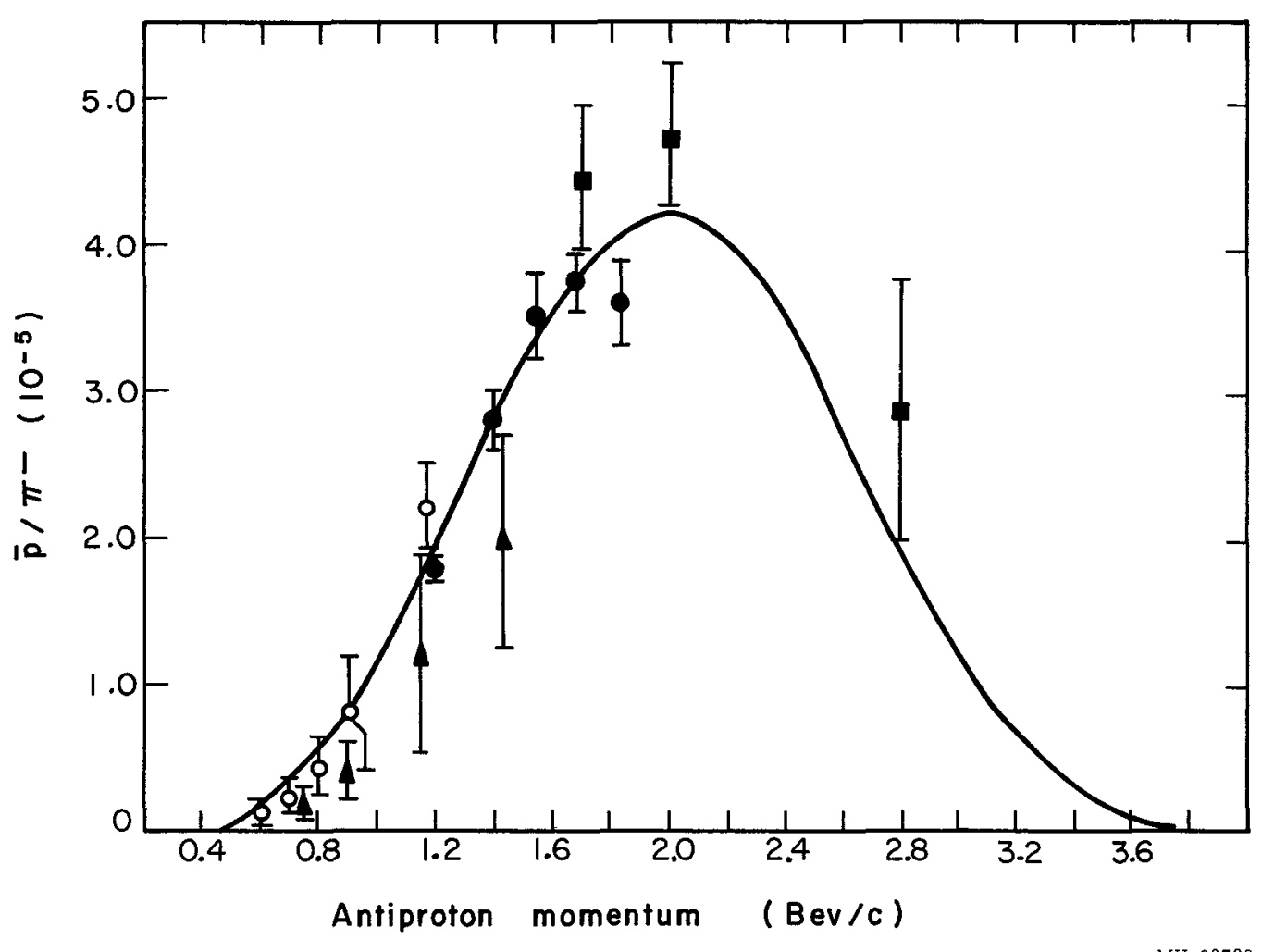

Fig. 10. Momentum distribution for antiprotons produced by approx 6-Bev protons on carbon and beryllium. The experimental points are taken from Table II. The curve is calculated by a statistical model. 


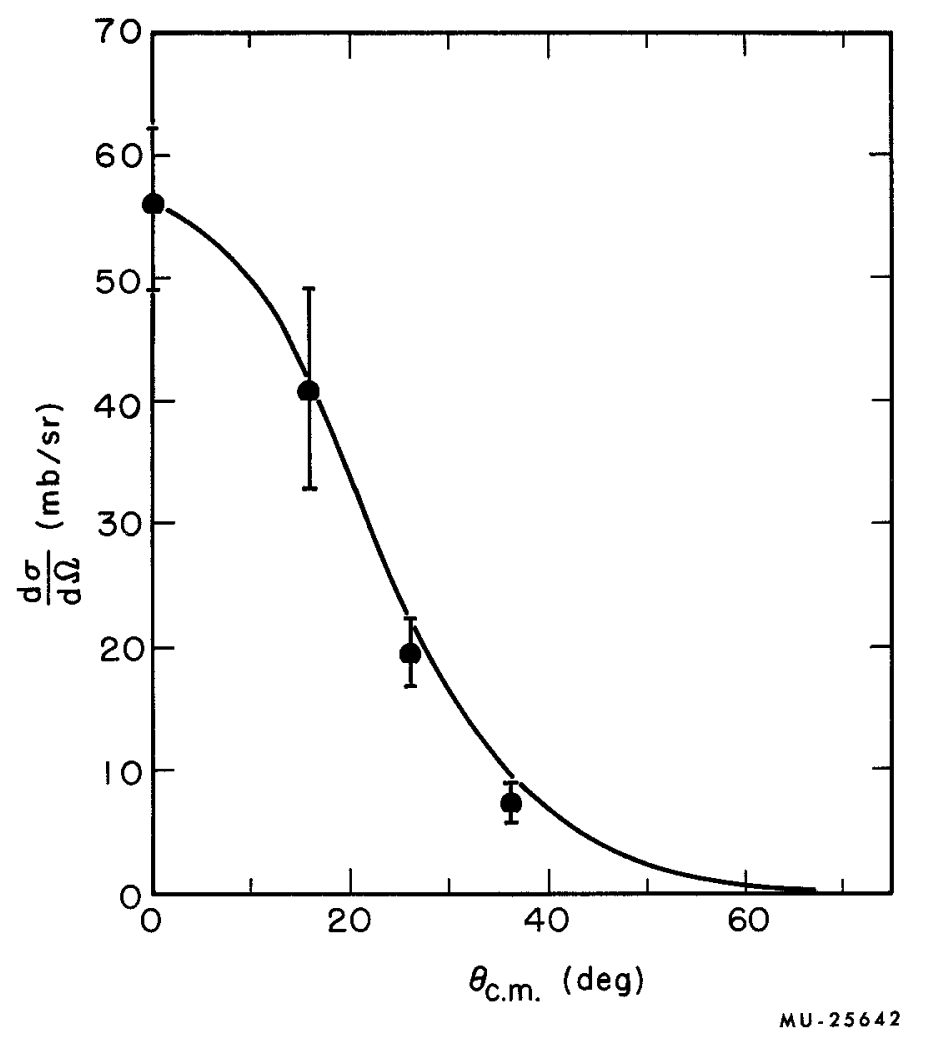

Fig. 11. Angular distribution of $\bar{p}-\mathrm{p}$ elastic scattering at $534 \mathrm{Mev}$. 


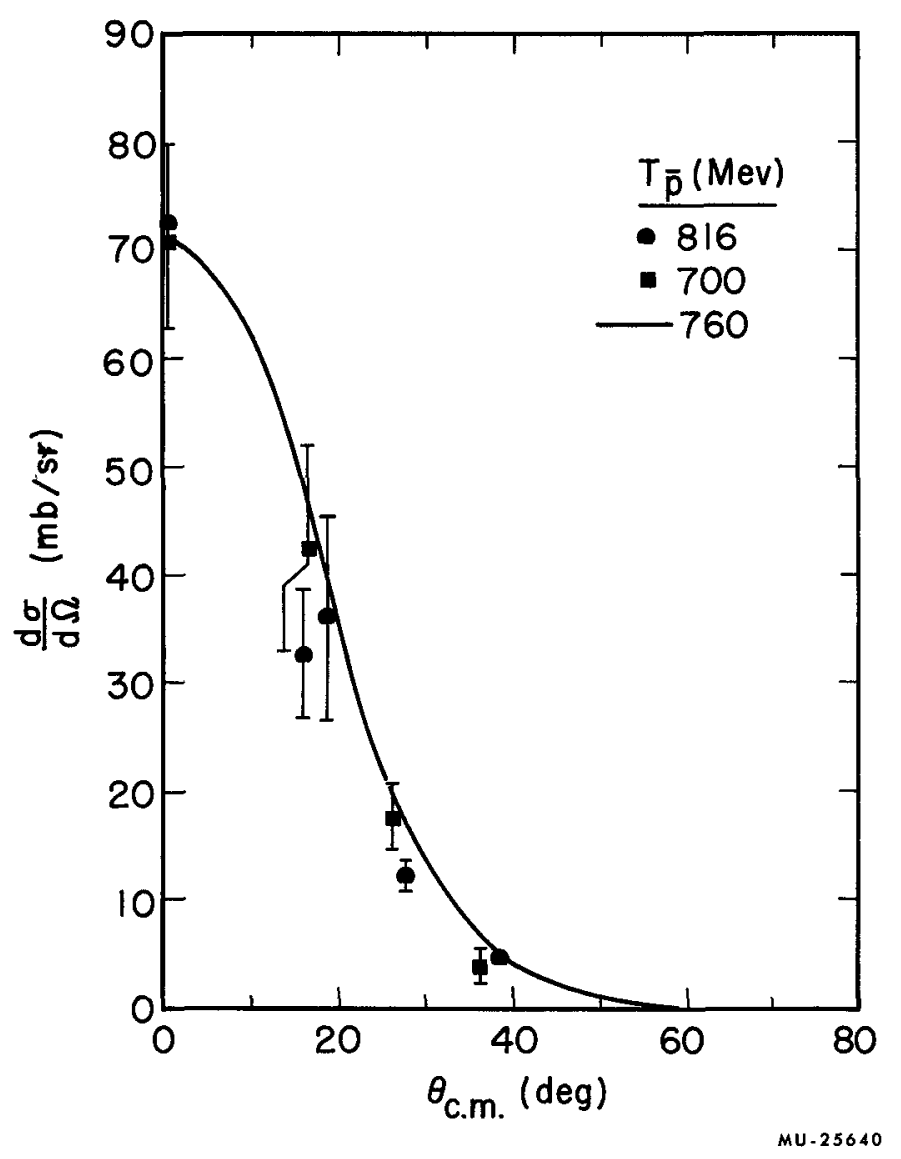

Fig. 12. Angular distribution of $\bar{p}-\mathrm{p}$ elastic scattering at 700 and $816 \mathrm{Mev}$. 


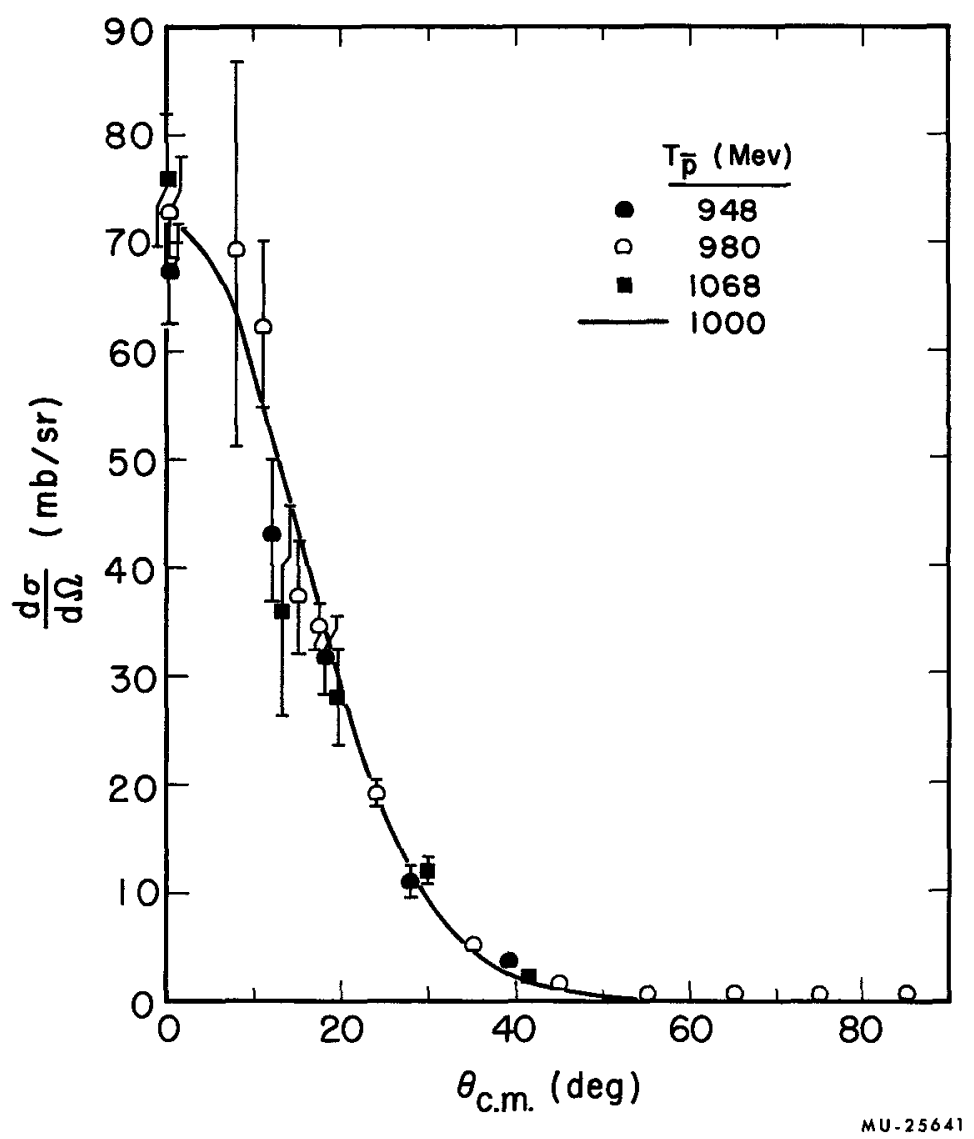

Fig. 13. Angular distribution of $\bar{p}-p$ elastic scattering near 1 Bev. The $980-\mathrm{Mev}$ points are from Armenteros et al. (reference 24). 


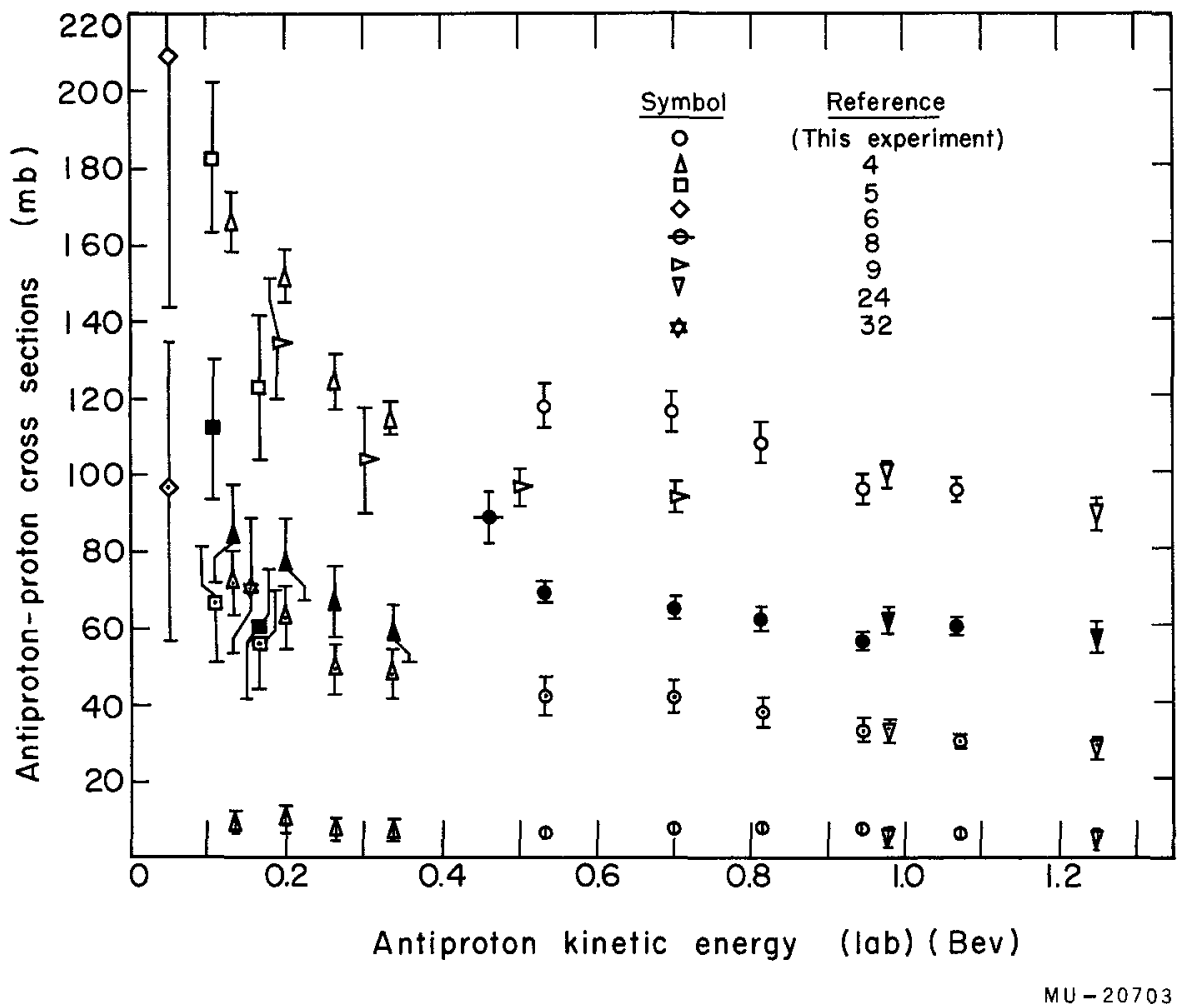

Fig. 14. Shown are $\bar{p}-\mathrm{p}$ cross sections as a function of antiproton kinetic energy. The open symbols are total cross sections; closed symbols are inelastic cross sections (for $\mathrm{T}_{\overline{\mathrm{p}}}<288 \mathrm{Mev}$ they are annihilation cross sections); open symbols encircling a dot are elastic cross section; open symbols crossed by a vertical line at the bottom of the figure are charge-exchange cross sections. The various types of symbols refer to different experiments; the references are correlated with the symbols in the upper right corner of the figure. 


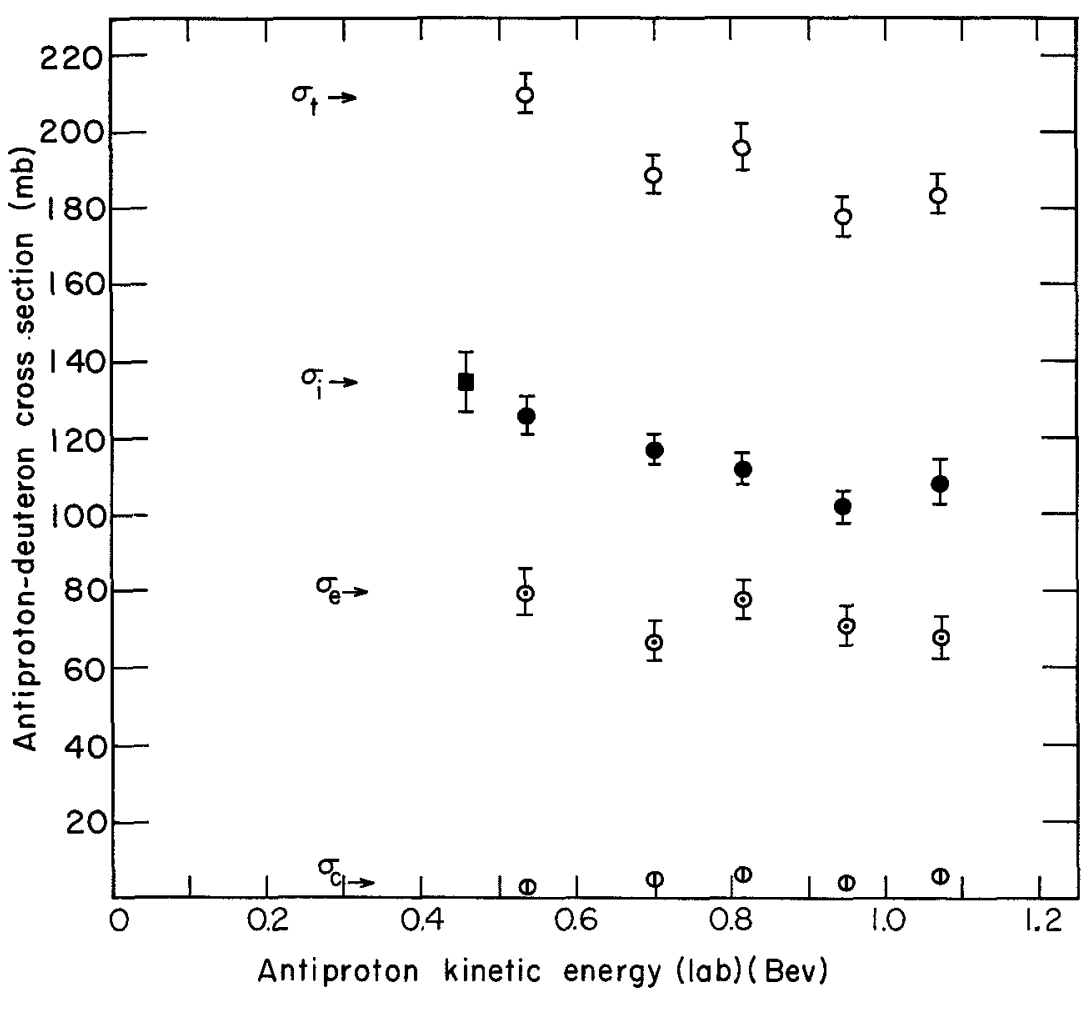

$M U-20708$

Fig. 15. Energy dependence of $\bar{p}-d$ cross sections.

Square symbol indicates a result from reference 8. 


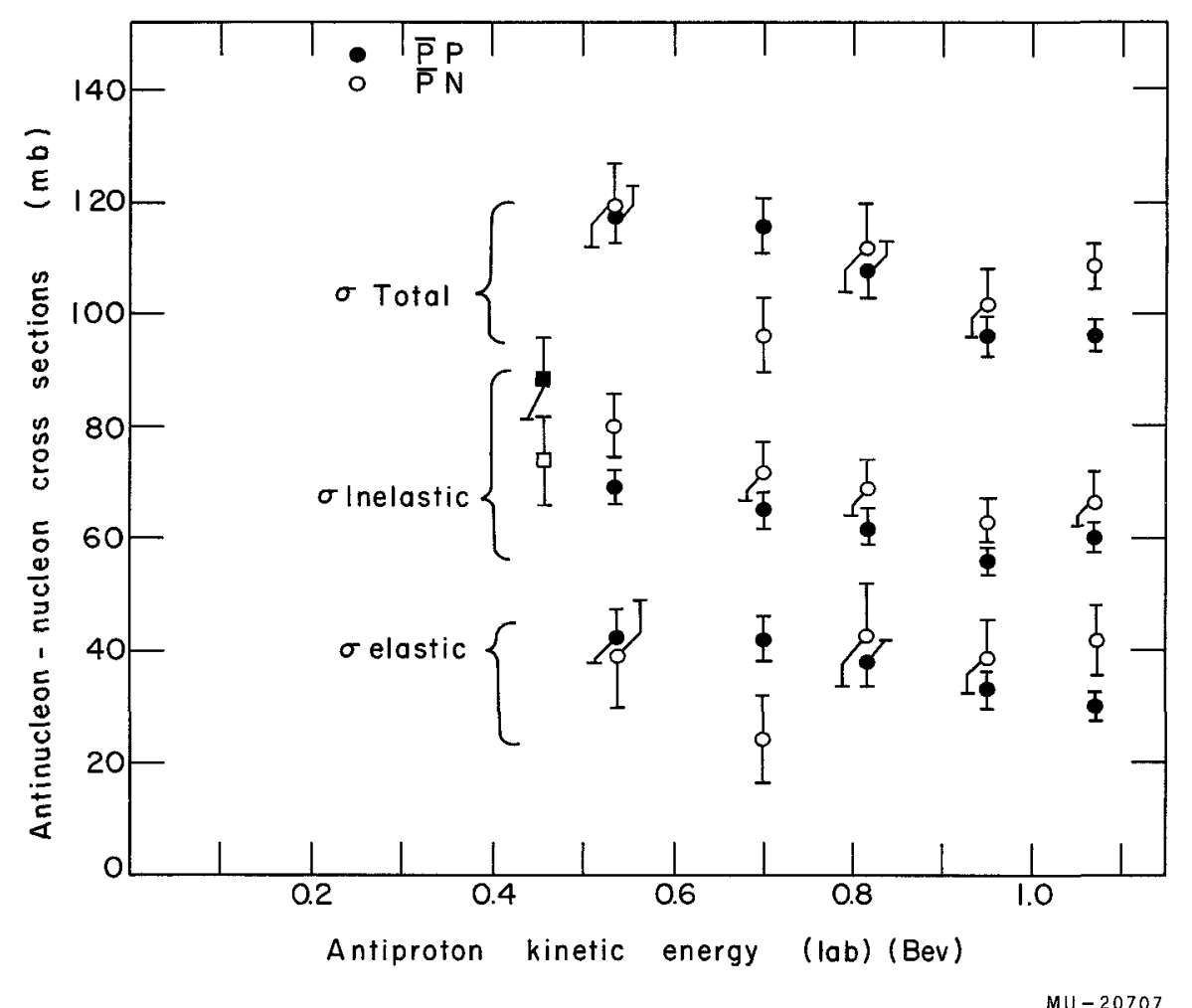

Fig. 16. Comparison of $\bar{p}-p$ and $\bar{p}-n$ cross sections in the energy range 450 to $1068 \mathrm{Mev}$. 